\title{
Dehydration effects from contrails in a coupled contrail-climate model
}

\author{
U. Schumann ${ }^{1}$, J. E. Penner ${ }^{2}$, Yibin Chen ${ }^{2}$, Cheng Zhou ${ }^{2}$, and K. Graf ${ }^{1}$ \\ ${ }^{1}$ Deutsches Zentrum für Luft- und Raumfahrt, Institut für Physik der Atmosphäre, Oberpfaffenhofen, Germany \\ ${ }^{2}$ University of Michigan, Department of Atmospheric, Oceanic, and Space Sciences, Ann Arbor, Michigan, USA \\ Correspondence to: U. Schumann (ulrich.schumann@dlr.de)
}

Received: 20 June 2015 - Published in Atmos. Chem. Phys. Discuss.: 17 July 2015

Revised: 16 September 2015 - Accepted: 23 September 2015 - Published: 8 October 2015

\begin{abstract}
The uptake of water by contrails in icesupersaturated air and the release of water after ice particle advection and sedimentation dehydrates the atmosphere at flight levels and redistributes humidity mainly to lower levels. The dehydration is investigated by coupling a plumescale contrail model with a global aerosol-climate model. The contrail model simulates all the individual contrails forming from global air traffic for meteorological conditions as defined by the climate model. The computed contrail cirrus properties compare reasonably with theoretical concepts and observations. The mass of water in aged contrails may exceed $10^{6}$ times the mass of water emitted from aircraft. Many of the ice particles sediment and release water in the troposphere, on average $700 \mathrm{~m}$ below the mean flight levels. Simulations with and without coupling are compared. The drying at contrail levels causes thinner and longer-lived contrails with about $15 \%$ reduced contrail radiative forcing (RF). The reduced RF from contrails is on the order of $0.06 \mathrm{~W} \mathrm{~m}^{-2}$, slightly larger than estimated earlier because of higher soot emissions. For normal traffic, the RF from dehydration is small compared to interannual variability. A case with emissions increased by 100 times is used to overcome statistical uncertainty. The contrails impact the entire hydrological cycle in the atmosphere by reducing the total water column and the cover by high- and low-level clouds. For normal traffic, the dehydration changes contrail RF by positive shortwave and negative longwave contributions on the order of $0.04 \mathrm{~W} \mathrm{~m}^{-2}$, with a small negative net RF. The total net $\mathrm{RF}$ from contrails and dehydration remains within the range of previous estimates.
\end{abstract}

\section{Introduction}

Contrail ice particles grow by the uptake of humidity from ambient ice-supersaturated air masses and release their water content after sedimentation or advection with the wind into regions with lower relative humidity. Knollenberg (1972) derived the ice mass inventory in a contrail for a single aircraft from measurements and found that the water present as ice in the contrail exceeds that in the original aircraft exhaust by at least 4 orders of magnitude. Hence, contrails dry or dehydrate the atmosphere at places where they form, and redistribute humidity to places in the atmosphere where they sublimate (Fahey and Schumann, 1999). Small relative changes of humidity in the troposphere and small absolute changes in the tropopause region have large effects on radiative forcing (Riese et al., 2012). Ice is far more efficient in radiative forcing than water vapor (Meerkötter et al., 1999; Chen et al., 2000; Fusina et al., 2007; Wilcox et al., 2012). The redistribution of humidity may make contrails thinner. In regions with heavy air traffic, contrail cirrus persistence can modify or even suppress natural cirrus formation (Unterstrasser, 2014), with consequences for radiative forcing (Burkhardt and Kärcher, 2011). Falling ice particles may enhance precipitation from mixed-phase or warm clouds at lower altitudes by increasing humidity and thus the liquid water content or by the Wegener-Findeisen-Bergeron process, both of which are thought to increase the likelihood of precipitation (Murcray, 1970; Korolev and Mazin, 2003; Yun and Penner, 2012). Dehydration from contrails may follow similar processes as dehydration by thin cirrus at the tropical tropopause (Jensen et al., 1996; Fueglistaler et al., 2009).

Contrails have been investigated in many observational and numerical studies (Schumann, 2002; Mannstein and 
Schumann, 2005; Burkhardt et al., 2010; Heymsfield et al., 2010; Yang et al., 2010; Unterstrasser and Gierens, 2010b; Minnis et al., 2013; Lewellen, 2014; Voigt et al., 2015). Nevertheless, the dehydration effects from contrails are not well known. Previous assessments of the climate impact of aviation (Schumann, 1994; Brasseur et al., 1998, 2015; Penner et al., 1999; Sausen et al., 2005; Lee et al., 2009, 2010; Boucher et al., 2013) discussed the dehydration effects from contrails qualitatively. Burkhardt and Kärcher (2011) were the first to quantify the dehydration effects within a global climate model. Contrail formation was treated as a sub-gridscale (SGS) process which included a separate cloud class for young contrails. They found that contrail cirrus causes a significant decrease in natural cloudiness, which partly offsets their warming effect. They estimated the cooling from reduced cirrus at about $7 \mathrm{~mW} \mathrm{~m}^{-2}$ and called for further work to more reliably quantify this effect.

Observations show ice particles precipitating from contrails in ice-supersaturated air (Heymsfield et al., 1998) and $\sim 2 \mathrm{~km}$ deep fall streaks of quickly falling large ice particles below individual contrails on horizontal scales of $\sim 5 \mathrm{~km}$, far smaller than global-model grid scales (Schumann, 1994; Atlas et al., 2006). Details of fall streaks below individual contrails were simulated in large-eddy simulations (LESs) (Jensen et al., 1998; Unterstrasser et al., 2012). Such fall streaks could not appear if the cirrus clouds are represented by mean values in the large grid cells of a global model. Obviously, the large-scale separation between individual contrails and global scales makes it difficult to assess the global impact of dehydration from contrails.

A contrail prediction model, CoCiP (Contrail Cirrus Prediction model), has been developed to simulate the formation and decay of all individual contrail segments for given air traffic and ambient meteorology (Schumann, 2012) including contrail-induced radiative forcing (Schumann et al., 2012b). CoCiP uses a simplified model designed to approximate the essential contrail physics for efficient simulation of contrails from global traffic over long periods. The contrail model bridges the gap between the different scales of the aircraft wake and the global atmosphere. Various of the model results compare reasonably well with observations (Voigt et al., 2010; Schumann, 2012; Jeßberger et al., 2013; Schumann and Graf, 2013; Schumann et al., 2013a, b). In the past, the model has been run in an offline mode for given meteorological fields, without exchange of humidity between contrails and background air.

In this study, the contrail model is coupled with the global climate model CAM3+-IMPACT (Community Atmosphere Model - Integrated Massively Parallel Atmospheric Chemical Transport; Wang and Penner, 2010), here also called CAM. The global model includes complex aerosol-cloud interactions, cirrus and ice supersaturation. The coupled CoCiP-CAM model is applied to quantify the impact of water exchange on contrail properties, large-scale humidity distribution, and background climate. In order to isolate the ef- fects of water uptake by ice particles without complicating effects from soot and other aerosols (Penner et al., 2009; Hendricks et al., 2011; Gettelman and Chen, 2013; Righi et al., 2013), this study is purposely restricted to the effects of exchanges of water. The ice nucleation properties of soot from aviation emissions might change when entering contrail ice (Zhou and Penner, 2014). This is a possibly important effect, which should be included in a future model application.

For small climate disturbances, to which aviation effects belong, the analysis of climate impact from free-running climate simulations is hampered by the noise inherent in such climate models because of the chaotic nature of atmosphere dynamics. For a climate model study with a diagnostic linear contrail model, Ponater et al. (2005) used a fuel consumption larger by a factor of 20 and Rap et al. (2010a) used contrail optical depth enhanced 100 times to obtain statistically significant results from 30- to 50-year climate simulations. This is a valid approach as long as the climate response to the disturbances is about linear. Gettelman and Chen (2013) and Chen and Gettelman (2013) were able to reduce the climate noise using a 20-year climate model (CAM5) simulation nudged to the pressure, winds and atmospheric and sea surface temperatures from a previous 1-year simulation. In order to quantify the effects of this nudging, one would need comparisons with and without nudging. Here, we try to overcome climate noise by using enhanced emissions and estimate the linearity of the responses.

\section{Methods}

\subsection{CAM3+-IMPACT model}

The method is a new combination of CoCiP with CAM3+IMPACT, with code changes to allow for coupling with exchange of water between contrails and ambient air. CAM3+-IMPACT is an updated version of the coupled aerosol-general-circulation-model described in Wang and Penner (2010) and Yun et al. (2013). CAM3 is the Community Atmosphere Model version 3, which simulates the atmosphere. Here, it is run using fixed sea surface temperature climatology with an overall time step of $1 \mathrm{~h}$ and a spatial resolution of $2^{\circ}$ in latitude and $2.5^{\circ}$ in longitude, with 26 vertical model levels up to about $3.5 \mathrm{hPa}$. IMPACT is the University of Michigan aerosol model, which treats a total of 17 aerosol types (Zhou and Penner, 2014). The model used here combines features added to CAM3 (called CAM3+) by Liu et al. (2007), Wang and Penner (2010), Yun and Penner (2012) and Yun et al. (2013). CAM3+ uses a two-moment cloud microphysics scheme for cloud ice, in which mass and number concentrations are predicted by prognostic equations. The two-moment scheme treats ice nucleation, evaporation, and melting, and it allows for ice supersaturation. The cloud fraction calculation accounts for new cloud cover by ice nucleation, treating homogeneous 
and heterogeneous nucleation of ice. The surface emissions included are for the year 2000 (Penner et al., 2009). The model has previously been compared with observations (Yun and Penner, 2012). For example, Wang and Penner (2010) showed that the model predicts the global distribution of ice supersaturation, cloud cover, ice water content, and ice crystal concentrations in reasonable agreement with observations.

\subsection{The contrail simulation model CoCiP}

$\mathrm{CoCiP}$ is a Lagrangian model which traces individual contrail segments forming along flight routes for many flights. The model is documented and discussed in Schumann (2012). In the following, the major features are explained with a few modifications. CoCiP simulates the lifecycles of contrails from their formation behind individual aircraft until final dissipation. Contrails are assumed to form when the Schmidt-Appleman criterion is satisfied for a given ambient temperature and humidity, a given fuel $\left(\mathrm{H}_{2} \mathrm{O}\right.$ emission index 1.24 , combustion heat $43.2 \mathrm{MJ} \mathrm{kg}^{-1}$ ), and a given overall propulsion efficiency (Schumann, 1996). The model assumes that the soot particles emitted into the young exhaust plume act as condensation nuclei for contrail formation when humidity exceeds liquid saturation. The resultant droplets freeze soon thereafter because of ambient temperature below homogeneous freezing limits. In the wake phase, some ice particles are lost by adiabatic warming or by mixing with dry ambient air. The initial contrail properties (depth, width, number of ice particles, initial ice water content) are computed for given aircraft types. (The importance of aircraft size, speed, fuel consumption, and emissions for contrail properties was the subject of several recent studies (Lewellen and Lewellen, 2001; Naiman et al., 2011; Voigt et al., 2011; Jeßberger et al., 2013; Schumann et al., 2013b; Unterstrasser and Görsch, 2014).) The contrail advection and the shear- and turbulence-driven spreading and mixing of plume air with ambient air are simulated with a Gaussian plume model. Contrails spread vertically mainly by turbulent mixing excited by shear and limited by stable stratification. In the model, particle sedimentation and differential radiative heating contribute to enhanced vertical diffusivity. Shear tends to distort plumes into vertically thin sheets enhancing vertical mixing. Horizontal diffusivities are larger because horizontal motions are not limited by stratification. The contrail bulk ice physics is approximated as a function of ice water content and ice particle number $\left(N_{\text {ice }}\right)$ per flight distance assuming saturation inside the contrail, which is justified for dense ice clouds or slow humidity changes (Korolev and Mazin, 2003; Kaufmann et al., 2014). The local ice particle concentration $\left(n_{\text {ice }}\right)$ is computed from the number of ice particles per flight distance divided by the plume cross section. After contrail formation, the contrail ice water content grows by the uptake of ambient humidity entering the plume by mixing with ambient ice-supersaturated air. When mixing with subsaturated air, the ice water content shrinks accordingly. The number of contrail ice particles is modeled as a function of soot emissions with some parameterized losses during the wake vortex phase of the contrail. The number of ice particles per unit plume length stays constant in the model except for parameterized losses by ice particle aggregation and turbulent mixing. (For a discussion of the aggregation model used, see Kienast-Sjögren et al. (2013).) In each contrail segment, the volume mean particle radius $r_{\mathrm{vol}}$ is computed from the volume of the ice and the particle number. For local optical depth and radiative forcing (RF) analysis, an effective radius $r_{\text {eff }}$ is computed assuming a fixed value of $C=r_{\mathrm{vol}} / r_{\mathrm{eff}}=0.9$ (Schumann et al., 2011b). The volume mean ice particle size is used to compute the mean fall speed (Spichtinger and Gierens, 2009). The vertical motion of the contrail follows the sum of ambient vertical velocity and fall speed. Because of crystal size dispersion, sedimentation also contributes to vertical widening of the plume cross section. The contrails terminate when all ice water content is sublimated (by mixing with dry air, e.g., during subsidence) or by precipitating below the lower boundary of the $\mathrm{CoCiP}$ domain. Contrail cover is computed on a fine grid with $5000 \times 3600$ longitude $\times$ latitude grid cells (about $5 \mathrm{~km}$ horizontal resolution) based on a threshold of 0.1 for optical depth (at $550 \mathrm{~nm}$ ), accounting for overlapping with other contrails and with ambient cirrus. Hence, a thin contrail overlapping with other thin cirrus may enlarge cover by enhancing the total optical depth beyond the threshold. The radiative forcing (RF) induced by contrails is computed from the sum of the contributions from each contrail; for each contrail, the RF is computed as a function of contrail properties and top-of-the-atmosphere radiances (Schumann et al., 2012b). The model is driven by air traffic waypoint data. Here, we use a global data set for the year 2006, including about 80000 flights day $^{-1}$, as provided within the ACCRI (Aviation Climate Change Research Initiative) project (Wilkerson et al., 2010; Brasseur et al., 2015). The fuel consumption and the corresponding water emissions from aircraft engines are available with these waypoint data. The overall propulsion efficiency, mostly between 0.2 and 0.4 , is deduced from the given speed, fuel consumption and thrust. The number of soot particles emitted is set to be proportional to the fuel consumption with a fixed emission index $\left(10 \times 10^{14} \mathrm{~kg}^{-1}\right)$. The emission index used here is larger than in earlier studies $\left(3.57 \times 10^{14} \mathrm{~kg}^{-1}\right)$ because recent experimental data indicate that modern aircraft emit more (by number) soot particles acting as contrail ice nuclei than estimated earlier (Schumann et al., 2013b).

CoCiP simulates contrail segments for each flight from departure until arrival for a maximum lifetime, set to $36 \mathrm{~h}$ in this application. (Ages up to about 1 day have been observed (Minnis et al., 1998; Haywood et al., 2009; Vázquez-Navarro et al., 2015).) In the original code version, this required frequent readings of the input files. To reduce computing time, we split the traffic data into hourly data. For each hour of 
integration over the year, first the contrail segments from the previous flights, if existing, are integrated forward in time over the next hour or until they die out. Thereafter, contrails from the new flight segments occurring during the hour are treated. Contrails remaining active at the end of the time step are saved for the next integration step.

The CoCiP results depend on various critical model parameters; see Table 2 in Schumann (2012). In particular, plume diffusivities are modeled as in Schumann and Graf (2013), with vertical plume diffusivities computed for $w_{N}^{\prime}=0.22 \mathrm{~m} \mathrm{~s}^{-1}$, and the vertical diffusivity is enhanced when radiative heating in the contrails causes convective instability. With respect to particle losses, we found that the second-order Runge-Kutta scheme for integration of the prognostic equations is stable and accurate enough without the need for iterations, reducing computing time. We also found, partially because of a compensating code error in the Runge-Kutta scheme, that the loss of particles due to mesoscale fluctuations has a small impact on the results and is no longer required (parameters $E_{T}=0.1$ and $E_{\text {meso }}=0$; see Table 2 of Schumann, 2012). The humidity seen by Co$\mathrm{CiP}$ in the troposphere is assumed to be enhanced by a factor of $1 / \mathrm{RHi}_{\mathrm{c}}\left(\mathrm{RHi}_{\mathrm{c}}=0.9\right)$ compared to what is provided by the host model to account for SGS variability and possible systematic deviations from observations. In a previous study, we used numerical weather prediction results from the European Center for Medium-Range Weather Forecasts (ECMWF) with an SGS factor of $\mathrm{RHi}_{\mathrm{c}}=0.8$ (Schumann and Graf, 2013). From the results of the present study, we learn that $\mathrm{RHi}_{\mathrm{c}}=1$ appears to give satisfactory results and should be used in future applications.

\subsection{The coupling of CoCiP to CAM}

CAM calls CoCiP as a subroutine each time step, providing the most recent meteorological fields as input. The fields include three-dimensional (3-D) fields of wind, temperature, humidity, ice water content, and cloud cover as a function of pressure. In addition, two-dimensional fields are provided for surface pressure, outgoing longwave radiation, reflected shortwave radiation, and incoming solar direct radiation. Co$\mathrm{CiP}$ interpolates in these fields linearly in space and time to obtain the values at any position.

In the offline mode, each contrail segment is simulated for the given ambient meteorological fields without changing background meteorology. This simplification is unavoidable when CoCiP is driven by the output of numerical weather prediction models, as has been done in the past. The offline mode allows for the efficient simulation of the contrails from millions of flights. For the coupled model, CoCiP is run either offline or online.

In the online mode, CoCiP returns effective emissions (besides $\mathrm{H}_{2} \mathrm{O}$, the code can also treat soot emissions) from aircraft after contrail processing. CoCiP accounts for the emissions exchanged between the background atmosphere and the contrails per time step and per CAM grid cell by tracking the 3-D-fields "EA", "EC" and "CA" (the sum of EA and $\mathrm{CA}$ is provided as a water source to CAM and treated as emissions). EA (engine to atmosphere) records the amount of emissions from aircraft engines directly to the atmosphere. EC (engine to contrail) is the amount emitted from aircraft engines into fresh contrails. Positive CA (contrail to atmosphere) values are the amounts released from contrails to the atmosphere; negative $\mathrm{CA}$ values are the amounts taken up by contrails from the atmosphere. The emissions are split into EA and EC during contrail formation as a function of the initial ice water content inside the freshly formed contrails relative to the amount of water emitted from the engines. Hence, if no contrail forms, EA from this flight contains all emissions and the contribution to EC is 0 . After contrail initiation, in growing contrails, the water contribution to CA becomes negative because contrail ice grows by the uptake of ambient humidity. Later during the contrail life cycle, the contrail provides a positive CA contribution when ice sublimates, releasing water to the atmosphere. The local sign of CA depends on the mix of growing and shrinking contrails within the grid cell. For diagnostics, CoCiP records the inventory of the amount of emissions stored inside contrail particles per CAM grid cell in a further 3-D field as a function of time. The sum of fields EA and CA and this inventory include all aircraft emissions in the CoCiP domain. Hence, the $\mathrm{H}_{2} \mathrm{O}$ mass passed between CoCiP and CAM is conserved. To reduce storage requirements, $\mathrm{CoCiP}$ operates on a limited altitude domain where contrails form, covering 18 CAM model levels, from 916 to $100 \mathrm{hPa}$. Aircraft emissions outside this altitude range (e.g., from airports) are included in CAM separately in a consistent manner.

To avoid negative vapor concentrations in regions with many contrails forming during a time step, CoCiP accounts for local $\mathrm{H}_{2} \mathrm{O}$ exchange between the contrails and background air during the integration time step. For this purpose, CoCiP uses a local copy of the background $\mathrm{H}_{2} \mathrm{O}$ concentration field provided by CAM and subtracts from it the amount of water vapor uptake by a contrail (and adds any released contrail water) immediately. The contribution from each contrail segment is distributed over contrail neighboring grid points depending on the respective distances, keeping $\mathrm{H}_{2} \mathrm{O}$ mass conserved. Hence, the next contrail during the same time step interval finds less humidity and is thinner. In this method, the results depend on the sequence of flights. The aircraft which flies first has a thicker contrail than aircraft later in the waypoint input. The accuracy of this approach depends on the ratio of the time step to the contrail lifetime. The accuracy increases for smaller time step sizes.

We note that the coupling between $\mathrm{CoCiP}$ and CAM transfers grid cell mean values from CAM to CoCiP and the sum of all contrail sources or sinks within a grid cell back from CoCiP to CAM. As a consequence, the mass of $\mathrm{H}_{2} \mathrm{O}$ uptake by a contrail during the time step is spread over the grid cell immediately. Because of the large difference between 
Table 1. Run specification.

\begin{tabular}{llll}
\hline Run & $\begin{array}{l}\text { Coupling } \\
\text { method }\end{array}$ & $\begin{array}{l}\text { Emission } \\
\text { amounts }\end{array}$ & $\begin{array}{l}\text { Integration } \\
\text { period }\end{array}$ \\
\hline 0 & offline & nominal & 30 years \\
1 & online & $\begin{array}{l}\text { nominal } \\
\text { online }\end{array}$ & $\begin{array}{l}\text { 30 years } \\
1 \text { year }\end{array}$ \\
\hline
\end{tabular}

contrail scales (widths on the order of $0.1-10 \mathrm{~km}$ ) and grid scales (about $200 \mathrm{~km}$ ), humidity variations on contrail scales cannot be resolved. A global model with far higher spatial resolution would be required to overcome this problem.

\subsection{Model runs}

Three runs were performed with CAM3+-IMPACT-CoCiP for this study; see Table 1. Run 0 is the non-coupled (offline) reference case in which CAM runs without aviation emissions, while $\mathrm{CoCiP}$ is run using nominal aircraft emissions. Here, CoCiP uses the meteorological fields from CAM in the same manner as it used numerical weather prediction results in the past (Schumann and Graf, 2013). Run 1 uses the coupled method (online) and simulates the effects of contrails on the hydrological cycle for nominal aircraft emissions. Run 2 uses aircraft emissions increased 100 -fold to enhance the aviation effects beyond climate noise. The results for runs 0 and 1 are from 30 years of simulation after several years of spinup. Because of limited computing resources, Run 2 includes just 1 year restarted from run 1 files.

\section{Results and discussion}

\subsection{CoCiP results}

This section describes the contrail results in some detail to explain the physics simulated and to compare them with observations. Some annual and global mean contrail properties for run 0 and 1 are given in Table 2. Unless otherwise stated, quantitative results are from run 1 . The interannual variability in the 30 -year mean values of $\mathrm{CoCiP}$ results as listed is small, and the run 1-0 differences in Table 2 are significant.

\subsubsection{Basic contrail properties}

\section{Traffic}

The emissions included in CAM are derived from $182.2 \mathrm{Tg}$ of annual fuel consumption, of which CoCiP analyses $83.2 \%$ (the rest comes from emissions near airports, which are added directly into the lower model levels of CAM). The global mean traffic density above $4.5 \mathrm{~km}$ altitude is $0.0072 \mathrm{~km}\left(\mathrm{~km}^{2} \mathrm{~h}\right)^{-1}$. About $92 \%$ of all flight segments occur in the Northern Hemisphere. Maximum traffic occurs

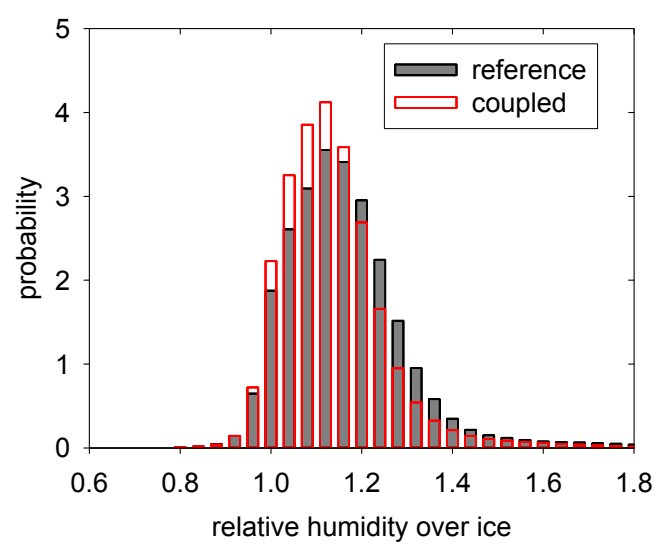

Figure 1. Probability density function (pdf) of relative humidity over ice in the freshly forming contrail segments without (black: reference case, run 0) and with (red: coupled, run 1) humidity exchange.

near $40^{\circ} \mathrm{N}$ over North America $\left(70-115^{\circ} \mathrm{W}\right)$, Europe $\left(7^{\circ} \mathrm{W}-\right.$ $\left.15^{\circ} \mathrm{E}\right)$, and Asia $\left(100-130^{\circ} \mathrm{E}\right)$.

\section{Contrail formation}

CoCiP computes the contrail properties for each given aircraft type. The average fuel consumption, mass, speed, and overall propulsion efficiency of contrail-forming aircraft are $4.60 \mathrm{~kg} \mathrm{~km}^{-1}, 116 \mathrm{Mg}, 225 \mathrm{~m} \mathrm{~s}^{-1}$, and 0.31 , respectively. The contrail-forming aircraft consume slightly more fuel $\left(5.33 \mathrm{~kg} \mathrm{~km}^{-1}\right)$ than the rest of the fleet. About $15 \%$ of all the flight segments cause contrail formation in the CAM atmosphere. About $7 \%$ occur in ice-supersaturated air causing persistent contrails. About $12 \%$ of all fuel is consumed in regions in which contrails form. (Fractions about two times larger were computed for ECMWF input with lower $\mathrm{RHi}_{\mathrm{c}}$ (Schumann et al., 2011a).) Contrail-forming aircraft fly mainly in the troposphere, at $10.9 \mathrm{~km}$ mean altitude, $220.3 \mathrm{~K}$ ambient temperature, $116 \%$ relative humidity over ice $(\mathrm{RHi}$, see Fig. 1), with mean ambient wind shear of $0.0023 \mathrm{~s}^{-1}$ and a Brunt-Väisälä frequency of $0.013 \mathrm{~s}^{-1}$. The computed RHi pdf (probability density function) is similar to observations (Immler et al., 2008). The global mean contrail temperature $\left(-53.1^{\circ} \mathrm{C}\right)$ is about 5 to $10 \mathrm{~K}$ below the mean threshold temperature for contrail formation and close to the values of $-52{ }^{\circ} \mathrm{C}$ deduced for contrails over the USA from day and night observations by Bedka et al. (2013) and also close to $-54.6{ }^{\circ} \mathrm{C}$ at cloud top deduced by Iwabuchi et al. (2012).

\section{Contrail properties}

CoCiP computes that there are about 3100 contrail segments of $36 \mathrm{~km}$ mean length present at a time on average within the CAM atmosphere. A total of $3 \times 10^{7}$ contrail segments are simulated per year. For given shear, stratification, and plume scales, the mean diffusivity values are 14 and $120 \mathrm{~m}^{2} \mathrm{~s}^{-1}$ 
Table 2. Annual and global mean contrail properties from run 0 and 1 with standard deviations $\sigma$ of interannual fluctuations for run 1 and percentage difference relative to run 0 .

\begin{tabular}{llrrr}
\hline Parameter & $\begin{array}{l}\text { Run } 0 \\
\text { offline }\end{array}$ & $\begin{array}{r}\text { Run 1 } \\
\text { online }\end{array}$ & $\begin{array}{r}\sigma \\
\text { Rel. } \\
\text { diff/\% }\end{array}$ \\
\hline Flight fraction with contrail formation & 0.158 & 0.154 & 0.001 & -3 \\
Flight fraction in ice-supersaturated air & 0.074 & 0.068 & 0.001 & -8 \\
Number of contrails at a given time & 2926 & 2862 & 53 & -2 \\
Relative humidity over ice at contrail formation $(\%)$ & 119 & 116 & 0.5 & -4 \\
Contrail optical depth $\tau$ in solar range & 0.335 & 0.289 & 0.002 & -14 \\
Cover by contrails with $\tau>0.1(\%)$ & 0.551 & 0.505 & 0.007 & -8 \\
Age of contrails $(\mathrm{h})$ & 1.9 & 2.0 & 0.01 & 5 \\
Ice crystals in contrails $\left(10^{12} \mathrm{~m}^{-1}\right)$ & 2.72 & 2.87 & 0.02 & 5 \\
Ice particle number concentration $\left(\mathrm{cm}^{-3}\right)$ & 0.388 & 0.438 & 0.003 & 13 \\
Ice water content $\left(\mathrm{mg} \mathrm{m}^{-3}\right)$ & 10.6 & 7.5 & 0.05 & -29 \\
Effective radius $(\mu \mathrm{m})$ & 45.4 & 35.1 & 0.17 & -23 \\
Total $\mathrm{H}_{2} \mathrm{O}$ mass inventory $(\mathrm{Tg})$ & 51.4 & 31.8 & 0.5 & -38 \\
Sedimentation distance in contrails $(\mathrm{km})$ & 0.713 & 0.734 & 0.008 & 3 \\
Contrail RFLW in North Atlantic region $(\mathrm{NAR})\left(\mathrm{W} \mathrm{m}^{-2}\right)$ & 1.05 & 0.88 & 0.06 & -16 \\
Contrail radiative forcing, longwave, RFLW $\left(\mathrm{W} \mathrm{m}^{-2}\right)$ & 0.171 & 0.143 & 0.002 & -16 \\
Contrail radiative forcing, shortwave, RFSW $\left(\mathrm{W} \mathrm{m}^{-2}\right)$ & -0.096 & -0.080 & 0.002 & -17 \\
Contrail radiative forcing, net, RFSW+RFLW $\left(\mathrm{W} \mathrm{m}^{-2}\right)$ & 0.074 & 0.063 & 0.001 & -14 \\
\hline
\end{tabular}

in vertical and horizontal directions. The contrails spread to $8 \mathrm{~km}$ mean width and $1 \mathrm{~km}$ mean total depth, with large variability. We define two results for the depth. The total depth describes the vertical variance of contrail properties in the Gaussian plume model; the effective depth is the ratio of cross-section area to contrail width (Schumann, 2012). The latter is smaller because shear causes a horizontally inclined and elongated cross section.

The aircraft emit on average $5.3 \times 10^{12} \mathrm{~m}^{-1}$ soot particles per flight distance. The contrails contain about $3 \times 10^{12} \mathrm{~m}^{-1}$ of ice particles per flight distance. Hence, about $56 \%$ of the ice particles survive wake, aggregation, and turbulent losses in the model. The ice water content (IWC) in contrails (and cirrus) correlates with ambient temperature and ambient relative humidity (Schiller et al., 2008). Figure 2 compares the pdf of computed IWC with the approximate IWC $/\left(\mathrm{mg} \mathrm{m}^{-3}\right)=\exp \left(6.97+0.103 T /{ }^{\circ} \mathrm{C}\right)($ Schumann, 2002). This parameterization was used, e.g., by Chen and Gettelman (2013) to compute the contrail IWC; it gives reasonable estimates for the mean but underestimates IWC variability.

On average, the IWC in contrails is found to be equivalent to an amount of water vapor at relative humidity over ice of about $15 \%$. This value is consistent with the mean RHi in the ambient air. A growing contrail may contain less ice water and a shrinking contrail more ice water than this mean value. Hence, as shown in Fig. 1, long-lived contrails also exist in subsaturated air (as observed by Kübbeler et al., 2011; Iwabuchi et al., 2012; and Kaufmann et al., 2014).

The total mean and median values of contrail properties per unit length vary over several orders of magnitude; see
Table 3. The values are averages over all contrail segments without accounting for contrail overlap. The median values are smaller than the mean values, which are controlled by a few very thick, old contrails. The ice mass per flight distance values $\left(6-50 \mathrm{~kg} \mathrm{~m}^{-1}\right)$ is of a magnitude similar to LES results (Unterstrasser and Gierens, 2010b; Lewellen, 2014). The integral numbers of Table 3 can be used to compute global mean contrail air density, ice water content, ice particle size, optical depth, geometrical depth, extinction coefficient, etc. For example, the ratio of volume per distance divided by the mean width (area per distance) defines an effective contrail depth (mean $\sim 800 \mathrm{~m}$, median $\sim 400 \mathrm{~m}, 1 / 2 \mathrm{~h}$ mean $145 \mathrm{~m})$. The ratio of ice water mass to emission water mass is about 180 for young (age $<0.5 \mathrm{~h}$ ) contrails, 1800 in the median, and $\sim 1.8 \times 10^{6}$ in the mean of these simulations. The ratio is close to one in the wake vortex phase (Vay et al., 1998) or in sublimating contrails. For old contrails in ice-supersaturated air, the ratio may be far larger than found by Knollenberg (1972), who measured in a contrail $18 \mathrm{~min}$ after its generation. The maximum values are limited by the number and mass of the largest ice particles relative to the mass of $\mathrm{H}_{2} \mathrm{O}$ emissions.

Because the number of ice particles is nearly constant per flight distance but variable in the plume cross section, the volume concentration $n_{\text {ice }}$ varies from more than $100 \mathrm{~cm}^{-3}$ in young contrails to less than $1 \mathrm{~L}^{-1}$ in aged contrails (see Fig. 2). The mean value depends strongly on how the average is defined. When averaging linearly over all contrail segments (many stay narrow), we obtain a high mean value of $n_{\text {ice }}$ of $86 \mathrm{~cm}^{-3}$. When counting all contrail ice particles globally and dividing by the total volume (segment 

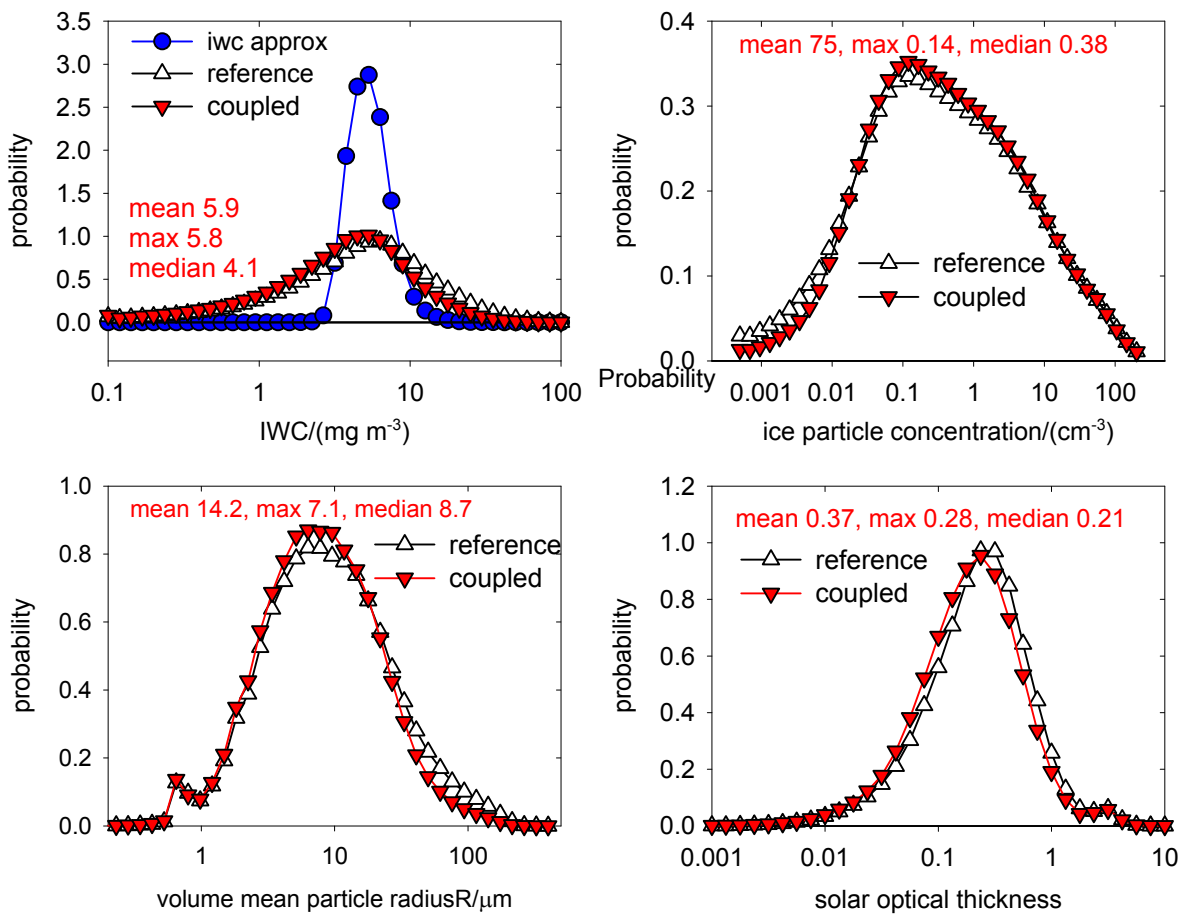

Figure 2. Pdf of contrail properties from CoCiP-CAM for run 0 (white symbols: reference) and 1 (red symbols: coupled). Ice water content (IWC; blue: computed from temperature; Schumann, 2002), ice particle concentration $\left(n_{\text {ice }}\right)$, volume mean particle radius $\left(r_{\mathrm{vol}}\right)$, and solar optical depth $(\tau)$ are all given in logarithmic scales. Mean-, median-, and maximum-probability values are listed for run 1.

Table 3. Contrail properties per length unit in run 1.

\begin{tabular}{llll}
\hline Parameter & Mean & Median & $\begin{array}{l}\text { Mean for } \\
\text { age }<0.5 \mathrm{~h}\end{array}$ \\
\hline $\mathrm{H}_{2} \mathrm{O}$ mass emission $\left(\mathrm{kg} \mathrm{m}^{-1}\right)$ & $6.56 \times 10^{-3}$ & $4.80 \times 10^{-3}$ & $6.34 \times 10^{-3}$ \\
Volume $\left(\mathrm{m}^{3} \mathrm{~m}^{-1}\right)$ & $6.62 \times 10^{6}$ & $2.01 \times 10^{6}$ & $1.15 \times 10^{5}$ \\
Air mass $\left(\mathrm{kg} \mathrm{m}^{-1}\right)$ & $2.54 \times 10^{6}$ & $8.02 \times 10^{5}$ & $4.23 \times 10^{4}$ \\
Ice mass $\left(\mathrm{kg} \mathrm{m}^{-1}\right)$ & $4.87 \times 10^{1}$ & $6.08 \times 10^{0}$ & $1.13 \times 10^{0}$ \\
Ice particles, $N_{\text {ice }}\left(\mathrm{m}^{-1}\right)$ & $2.89 \times 10^{12}$ & $2.21 \times 10^{12}$ & $3.99 \times 10^{12}$ \\
Width $(\mathrm{m})$ & $8.14 \times 10^{3}$ & $5.00 \times 10^{3}$ & $7.92 \times 10^{2}$ \\
$S=N_{\text {ice }} \pi r_{\text {area }}^{2}\left(\mathrm{~m}^{2} \mathrm{~m}^{-1}\right)$ & $1.11 \times 10^{3}$ & $4.80 \times 10^{2}$ & $1.39 \times 10^{2}$ \\
Optical depth $(\tau) \times$ width $(\mathrm{m})$ & $2.25 \times 10^{3}$ & $1.06 \times 10^{3}$ & $2.78 \times 10^{2}$ \\
Ratio ice mass $/ \mathrm{H}_{2} \mathrm{O}$ mass emission & $1.78 \times 10^{6}$ & $1.78 \times 10^{3}$ & $1.78 \times 10^{2}$ \\
\hline
\end{tabular}

length $\times$ cross-section area) of all contrail segments, we find that the volume is very large and dominated by wide, old contrails. Hence, this mean value of $n_{\text {ice }}$ is far smaller $\left(0.4 \mathrm{~cm}^{-3}\right)$.

The mean volume radius varies over a large range, from about half a micrometer to half a millimeter (see Fig. 2). The lower bound results from the water mass and the number of soot particles nucleating ice in fresh contrails. The upper size limit is determined by sedimentation. The fall speed reaches values on the order of $0.5 \mathrm{~m} \mathrm{~s}^{-1}$ for particle radii exceeding $100 \mu \mathrm{m}$; the average fall speed is $0.0026 \mathrm{~m} \mathrm{~s}^{-1}$. Particles sedimenting in supersaturated air may grow quickly. The lin- ear arithmetic mean particle radius $r_{\mathrm{vol}}$ is $14 \mu \mathrm{m}$. The median value of $r_{\mathrm{vol}}$ is smaller $(9 \mu \mathrm{m})$. These sizes are representative for young and narrow contrails. Alternatively, we compute a volume mean radius of the ensemble of all contrails from the total contrail ice volume divided by the total number of contrail ice particles and likewise an effective radius from the ratio of the total vertically projected particle cross-section area divided by the total particle volume, following common definitions (McFarquhar and Heymsfield, 1998). This results in far larger integral mean sizes: $r_{\mathrm{vol}}=27 \mu \mathrm{m}$ and $r_{\text {eff }}=35 \mu \mathrm{m}$. These large integral values are dominated by the aged contrails with the largest volume. 

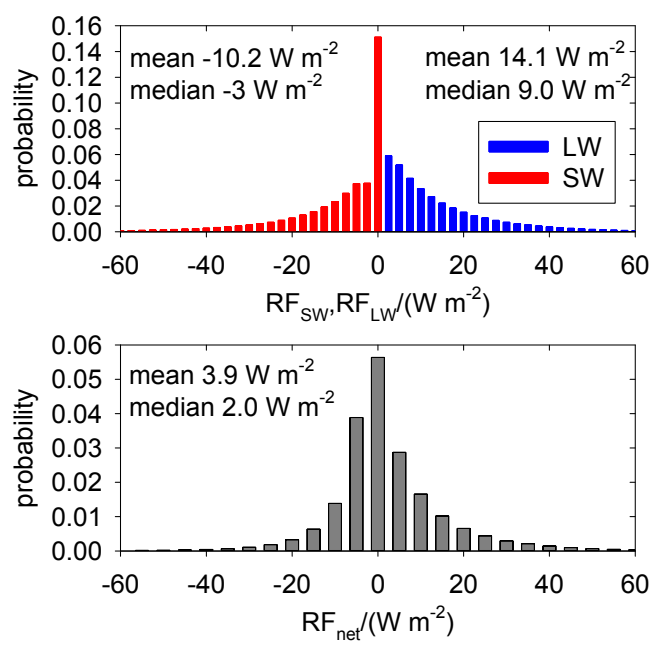

Figure 3. Pdf of local radiative forcing by contrails in the shortwave (red) and longwave (blue) ranges (top) and net RF (bottom).

These particle sizes appear far larger than usually assumed for linear contrails. Bedka et al. (2013) found an average particle effective radius of $9 \mu \mathrm{m}$ in MODIS satellite data. Larger mean particle sizes have been observed for contrail cirrus: $20-25 \mu \mathrm{m}$ (Minnis et al., 2013). The remote-sensing methods may underestimate the particle sizes because the largest particles may have fallen (e.g., in fall streaks) below a level visible to remote sensing from space.

The optical depth $\tau$ of contrails may be computed locally as a function of the particle cross-section $\pi r_{\text {area }}^{2}$ (with $r_{\text {area }}^{2}=$ $r_{\mathrm{vol}}^{3} / r_{\mathrm{eff}}$; Schumann et al., 2011b), volume-specific number concentration $n_{\text {ice }}$, and the effective geometrical depth of the contrail plume. For various contrail segments, $\tau$ varies strongly (see Fig. 2). $\tau$ is large for young contrails because of many ice particles grown by the uptake of ambient humidity in narrow plumes with large depths. This can be seen from observations and models (Voigt et al., 2011; Jeßberger et al., 2013). Later, $\tau$ may grow in rising air masses with increasing humidity but generally decreases and approaches 0 while the contrails spread laterally and finally sublimate. The pdf of $\log \tau$ has a negative skewness: a few contrails thicken, while most have small $\tau$, and some are subvisible. The same type of asymmetry in the pdf of $\log \tau$ has been simulated by Kärcher and Burkhardt (2013) for contrails and measured by Immler et al. (2008) for contrail cirrus. The global mean optical depth $\tau$ is 0.29 , which is close to values observed for young contrails (Voigt et al., 2011). The global mean value is slightly larger than the value for linear contrails derived by Bedka et al. (2013) from MODIS (0.19-0.26). Contrails detected with an automatic contrail tracking algorithm (ACTA) from Meteosat observations by Vázquez-Navarro et al. (2015) have very similar optical thickness (mean: 0.34, median: 0.24).

The RF induced by contrail segments varies strongly (see Fig. 3). In rough agreement with observations (Vázquez-
Navarro et al., 2015), individual contrail segments may cause local RF values in areas covered by contrails exceeding $60 \mathrm{~W} \mathrm{~m}^{-2}$, with mean values on the order of $10 \mathrm{~W} \mathrm{~m}^{-2}$. The frequent zero SW RF values result from nighttime contrails. The local net RF may be positive or negative and far larger than the mean value. Vázquez-Navarro et al. (2015) found larger mean values because their method mainly detects geometrically and optically thick contrails. The shape of the SW and LW RF pdfs is similar to theory predictions (Kärcher and Burkhardt, 2013), but negative RF values were not expected in that study.

The age of the simulated contrails varies between a few minutes and $36 \mathrm{~h}$. The mean age is computed as the arithmetic mean of all contrail segment ages. The computed mean contrail age is about $2 \mathrm{~h}$. The contrail ages tend to increase for decreasing ambient humidity (run 1 compared to run 0 ) because of reduced sedimentation for lower humidity. The upper limit of $36 \mathrm{~h}$ is reached only 18 times globally in $30-$ year simulations. Ages of individual contrails exceeding $10 \mathrm{~h}$ occur rarely (see Fig. 4; the pdf is generated from a $3 \%$ subsample of 1-year simulation data and, hence, misses the few contrails with the upper limit age of $36 \mathrm{~h}$ ). The lifetimes are within the range of results derived with ACTA from Meteosat contrail observations by Vázquez-Navarro et al. (2015).

The lifetimes depend among other things on vertical motions in the ambient air. In the model, the contrails experience larger mean uplift $(100 \mathrm{~m})$ than subsidence $(74 \mathrm{~m})$. Plume spreading in ambient ice-supersaturated air causes ice particle growth because the same ice particles share a growing amount of humidity. Sinking air warms adiabatically so that contrails sublimate. Rising air tends to increase relative humidity. Strong adiabatic uplift may cause strong growth of the ice particles so that they may start sedimenting and precipitate in fall streaks. Hence, quickly rising contrails may have shorter lifetimes than slowly rising ones. All these properties are consistent with findings from LES and observations (Iwabuchi et al., 2012; Lewellen, 2014).

\section{Comparison with a theoretical concept of sedimentation influence on optical depth}

An important metric for contrail radiative properties as a whole, independent of the definition of contrail width $W$ or contrail depth $D$, is the total projected surface area $S$ of all contrail ice particles per unit contrail length $\left(S=N_{\text {ice }} \pi r_{\text {area }}^{2}\right)$, where $N_{\text {ice }}$ is the number of ice particles per contrail length and $\pi r_{\text {area }}^{2}$ is the mean effective projected cross section of the ice particles (Schumann et al., 2011b; Lewellen et al., 2014; Lewellen, 2014). (Mean values are listed in Table 3.) The importance of $S$ can be seen from the fact that the optical depth $\tau$ of contrails is $\tau=Q_{\text {ext }} \mathrm{S} / \mathrm{W}$, where $Q_{\text {ext }}$ is the mean extinction efficiency and $W$ the effective width of the contrail. The product $W \tau=Q_{\text {ext }} S$ is known as total extinction and is important for the radiative forcing of a contrail at a given time (Unterstrasser and Gierens, 2010b). Hence, 


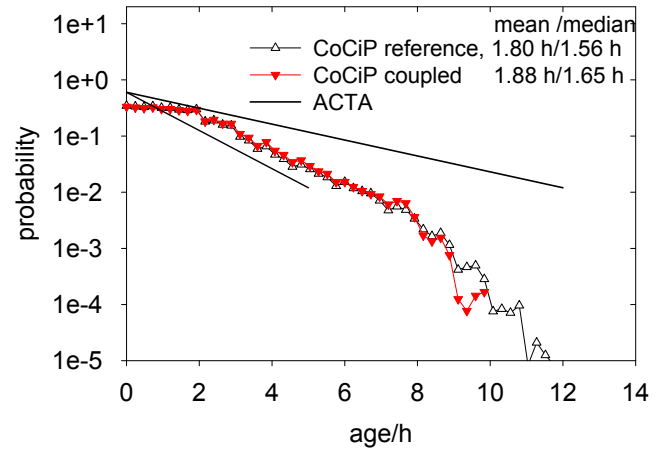

Figure 4. Pdf of contrail ages. Symbols for CoCiP runs 0 and 1 (significant below ages of about $8 \mathrm{~h}$ ), with given mean or median values. The straight lines enclose age results for contrails tracked with the ACTA algorithm in infrared Meteosat data (Vázquez-Navarro et al., 2015).

$\tau$ does depend on the width $W$ and its definition, but $W$ cancels out when computing the global radiative forcing RF, which is the sum of all contrail segment RF values weighted with contrail length and width divided by the Earth surface. The value of $S$ vs. contrail age is plotted in Fig. 5. We see $S$ increasing with contrail age for the first $2 \mathrm{~h}$ and then approaching a constant, which is about $10^{2}$ to $10^{4} \mathrm{~m}^{2} \mathrm{~m}^{-1}$ in these simulations. $S$ decreases for aged contrails in spite of increasing contrail width. The magnitude of $Q_{\text {ext }} S$ agrees with observations (Vázquez-Navarro et al., 2015). The initial growth comes from particle growth in ice-supersaturated air. Later, values are limited because large particles sediment quickly (Schumann, 1996). Lewellen (2014) noted the importance of the integral $\int S(t) \mathrm{d} t$ over the contrail lifetime as a measure for the total climate impact of the contrail. This integral has similarities with the energy forcing which we have discussed elsewhere (Schumann et al., 2012a). Since we did not save the integral value in our simulations, we approximate the integral by $S t_{\text {age }} / 2$. The results show that $\int S \mathrm{~d} t$ approaches asymptotic values on the order of $10^{8} \mathrm{~m} \mathrm{~s}$ for old contrails. The values are close to those reported by Lewellen (2014) from LES of contrails with particle-sizeresolving microphysics. He showed that the integral $S$ relates to fall speed and the sedimentation depth $\Delta z_{\text {sed }}$ by $\int S \mathrm{~d} t \cong \alpha N_{\text {ice }} \Delta z_{\text {sed }}$, where $\alpha=18 \pi \eta /\left(g \rho_{\text {ice }}\right)$ is a parameter resulting from the Stokes law for the particle terminal fall velocity $\left(\eta \cong 14 \times 10^{-6} \mathrm{~kg} \mathrm{~m}^{-1} \mathrm{~s}^{-1}\right.$ is the dynamic viscosity of air; $\rho_{\text {ice }} \cong 917 \mathrm{~kg} \mathrm{~m}^{-3}$ is the bulk density of ice; $g$ is gravity). The sedimentation depth $\Delta z_{\text {sed }}$ was computed within CoCiP for each contrail segment. Figure 5 shows that the CoCiP results are roughly consistent with the theory. The results illustrate the important link between the optical properties of contrails and ice particle sedimentation in ice-supersaturated air. The scatter around the mean $1: 1$ correlation indicates that the effective $S$ values depend also on other parameters: Lewellen (2014) noted the importance of the depth of the
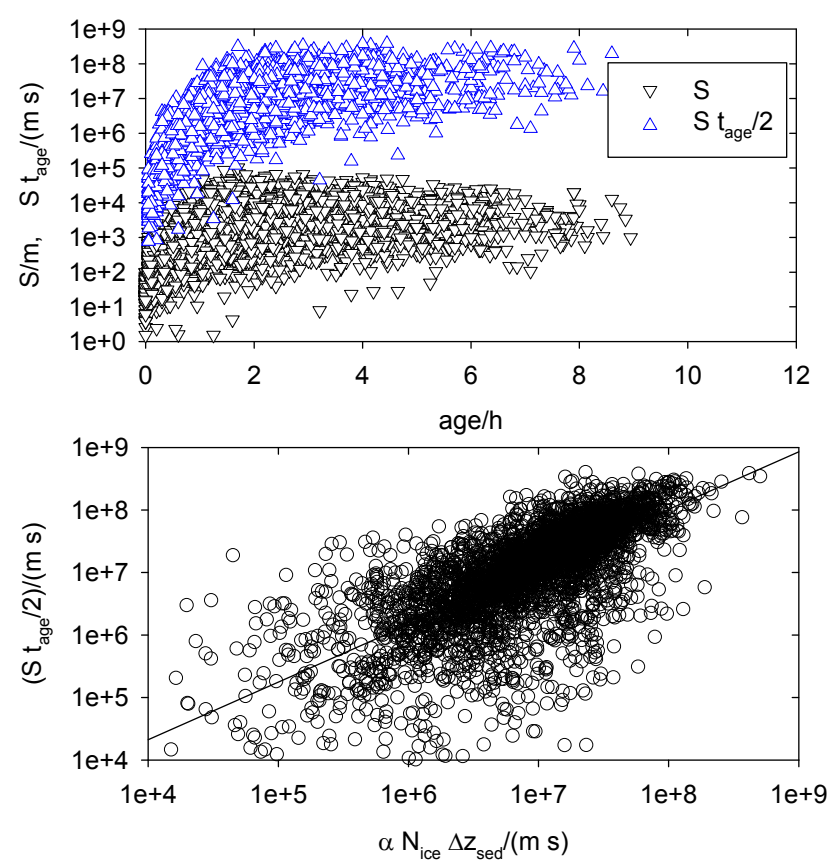

Figure 5. Ice particle cross-section area $S$ per contrail length (unit $\mathrm{m}^{2} \mathrm{~m}^{-1}$ ) and its approximated time integral $\int S \mathrm{~d} t \cong S t_{\text {age }} / 2$ (in $\mathrm{ms}$ ) vs. plume age $t_{\text {age }}$ (top panel) and vs. the approximating parameter suggested by Lewellen (2014) (see text). The line depicts a linear fit.

ice-supersaturated layer below flight levels. In addition, we have nonsteady and spatially variable meteorology and sizedependent fall speeds differing from the Stokes law. We see that the essential physics of contrail optical depth formation as simulated by $\mathrm{CoCiP}$ is similar to LES results.

\section{Comparison of contrail properties with observations from space}

In addition to the comparisons mentioned, we compare the computed contrail properties with satellite observations. Iwabuchi et al. (2012) used satellite pictures (MODIS) to identify linear contrails and derived their altitude and thickness from collocated space lidar (CALIPSO - Cloud-Aerosol Lidar and Infrared Pathfinder Satellite Observation) observations. The method was applied for the domain $15-85^{\circ} \mathrm{N}$ and $180^{\circ} \mathrm{W}-80^{\circ} \mathrm{E}$ (see Fig. 6). Contrails were detected mainly over the North Atlantic. Although we find a larger share of contrails over the continents, the vertical distribution of the contrails vs. latitude in the model is similar to that observed (see Fig. 7). Some of the simulated (and observed) contrails at low latitudes rise above $14 \mathrm{~km}$ altitude, above the maximum flight levels where contrails form $(13.1 \mathrm{~km})$. This is a consequence of rising air masses, as they occur in the tropics, over continents (Pauluis et al., 2008). The computed mean contrail altitude $(10.5 \pm 1.2 \mathrm{~km})$ is slightly lower than observed $(10.9 \pm 1 \mathrm{~km})$. Some of the low-level contrails 


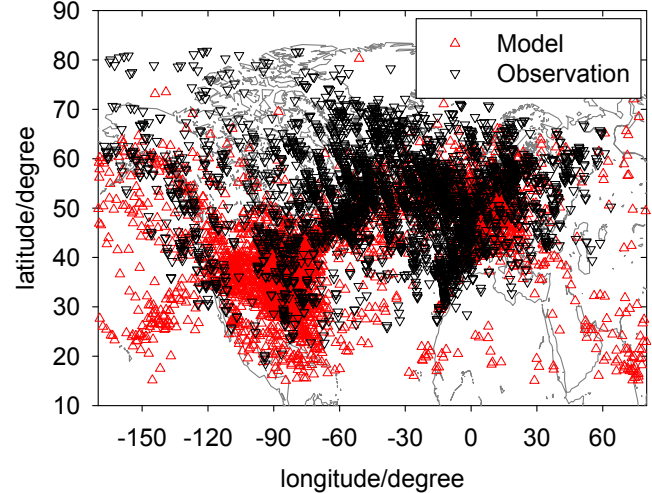

Figure 6. Contrail occurrence computed with CoCiP-CAM (red upward triangles; run 1) and analyzed from MODIS-CALIPSO observations (black downward triangles; data from Iwabuchi et al., 2012), for $180^{\circ} \mathrm{W}-60^{\circ} \mathrm{E}, 15-85^{\circ} \mathrm{N}$. The triangles represent single contrail events (a small random subset of computed contrails is plotted).

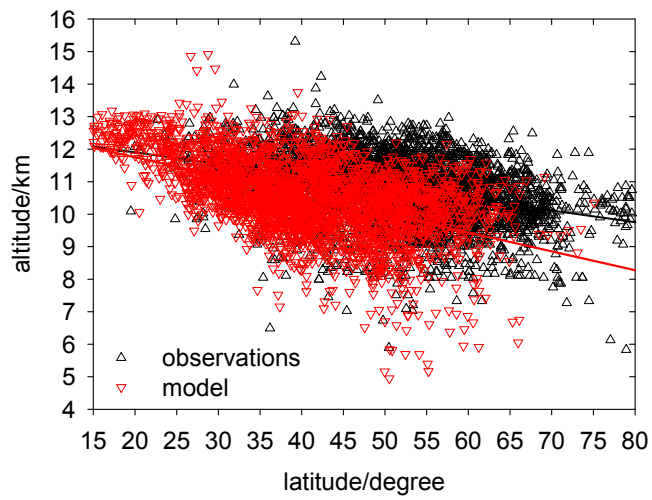

Figure 7. Contrail occurrence vs. latitude as in Fig. 6. Red symbols: CoCiP-CAM; black: MODIS-CALIPSO data from Iwabuchi et al. (2012). The colored lines are linear fits to the respective data.

may result over continents from aircraft during ascent or descent. Others may occur below thick high-level clouds and be missed by lidar observations.

Figure 8 shows that the pdf of optical depth from CoCiP is close to that derived from MODIS and CALIPSO. The differences between the model results for run 1 and 0 are significant but comparable to the differences between the measurements in the 2 years (with slightly different lidar properties; Iwabuchi et al., 2012). Figure 9 compares the computed and observed width and vertical geometrical depth of contrails. We note the large scatter of the data. Perhaps CoCiP slightly overestimates the total depth. The effective depth appears to fit the observations better. The contrail width pdf (not shown) is a maximum at zero width and decreases exponentially, with a $5 \mathrm{~km}$ median and an $8.1 \mathrm{~km}$ mean width. The width range of ACTA contrails is more limited $(7.8 \pm 2 \mathrm{~km})$ (Vázquez-Navarro et al., 2015).

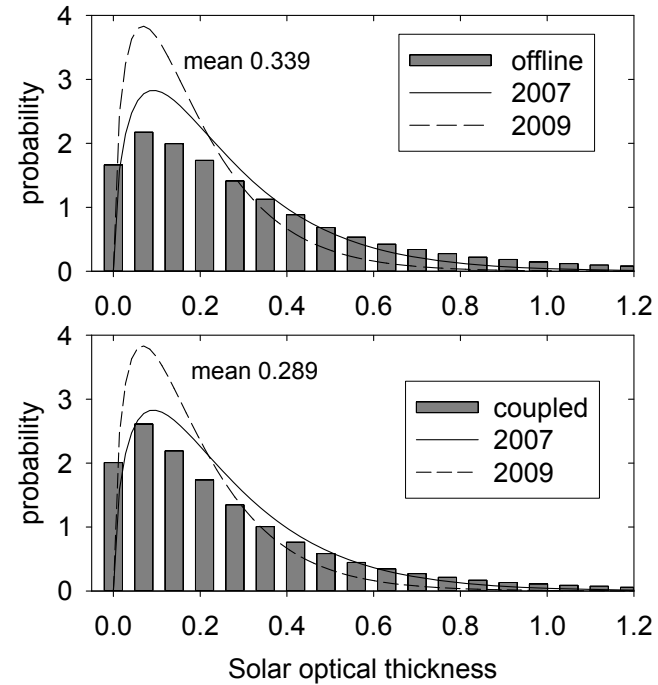

Figure 8. Pdf of solar optical depth of contrails in CoCiP-CAM simulations. Top: run 0; bottom: run 1 . The curves in both panels are the same and are gamma functions approximating MODISCALIPSO observations in 2007 and 2009 (full and dashed, respectively), as reported by Iwabuchi et al. (2012).

Figure 10 compares the difference in the diurnal cycle of cirrus cover and outgoing longwave radiation (OLR) between the North Atlantic region (NAR; $45-55^{\circ} \mathrm{N}, 10-45^{\circ} \mathrm{W}$ ) and a corresponding South Atlantic region (SAR; $45-55^{\circ} \mathrm{S}$, $\left.10-45^{\circ} \mathrm{W}\right)$ from the model with results from 8 years of satellite observations. Cirrus cloud cover (Ewald et al., 2013) and outgoing longwave radiation (Vázquez-Navarro et al., 2013) data were derived from Meteosat Second Generation (MSG) infrared satellite observations. The anomalies have 0 mean values. Air traffic density in the SAR is practically 0 , while traffic in the NAR shows a systematic double-wave diurnal cycle (Graf et al., 2012). Anomalies of cirrus cloud cover and OLR differences between NAR and SAR from MSG show similar patterns with a $2-4 \mathrm{~h}$ delay. This "aviation fingerprint" was used to quantify aviation-induced cirrus changes (Graf et al., 2012; Schumann and Graf, 2013). The delay can be interpreted as the time it takes to let ice particles grow (see Fig. 5) and spread from fresh contrails to extended cirrus cover. The results suggest that contrail cirrus contributes about $2 \%$ of cirrus cover and about $1 \mathrm{~W} \mathrm{~m}^{-2}$ of radiative forcing in this region. The diurnal cycle from the sum of Co$\mathrm{CiP}$ contrail cover and CAM cirrus cover and corresponding longwave radiances is consistent in shape and amplitude with the MSG results. They agree approximately also with results from the offline CoCiP-ECMWF combination in Schumann and Graf (2013).

Also, the interannual variability in the MSG results is comparable in magnitude to the variability in the CAM-CoCiP results. This suggests that $\mathrm{CoCiP}$ simulates most of the processes controlling this contrail cirrus signal. The ratio of 


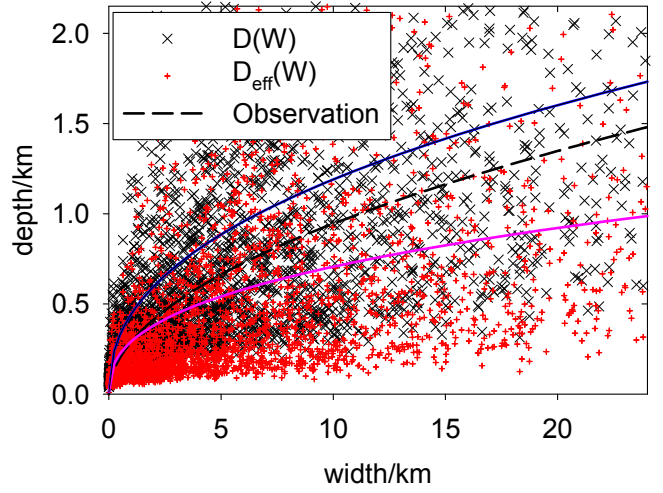

Figure 9. Contrail Gaussian plume depth $D$ (black), and effective depth $D_{\text {eff }}$ (red) vs. contrail width $W$ from CoCiP-CAM. The crosses show individual contrail results in the domain as in Fig. 6. The black and red curves show power-law regression results; $D / \mathrm{km}=0.68\left(\mathrm{~W} \mathrm{~km}^{-1}\right)^{0.373}$, and $D_{\text {eff }} / \mathrm{km}=0.454$ $\left(\mathrm{W} \mathrm{km}^{-1}\right)^{0.420}$. The black dashed curve is the corresponding regression $\left(D / \mathrm{km}=0.29\left(\mathrm{~W} \mathrm{~km}^{-1}\right)^{0.513}\right)$ as given by Iwabuchi et al. (2012).

regional LW RF to global LW RF (see Table 2) is 6.12 and 6.13 in runs 0 and 1 , respectively. The ratio was 5.71 in the previous study with ECMWF meteorology. This ratio was used to extrapolate the regional LW RF to the global RF. Hence, the coupling does not change the main conclusions from earlier CoCiP studies.

We looked for a local response of cirrus cover and OLR to dehydration following the diurnal traffic cycle. The results from CAM do not reflect such a diurnal cycle. Different timescales of contrail cirrus and dehydration effects would be important when discussing mitigation options. Also, Chen and Gettelman (2013) computed a far smaller amplitude of a double-wave diurnal cycle in global model results of LW $\mathrm{RF}$ for this region than observed. Hence, the dehydration effects of the contrails within CAM are either slow or not large enough to excite a semidiurnal cycle. Note that most contrails are thinner than $1 \mathrm{~km}$. Perhaps the coarse CAM grid cells (about $1 \mathrm{~km} \times 180 \mathrm{~km} \times 220 \mathrm{~km}$ ) smooth out any local response of cirrus to dehydration.

\section{Some global contrail properties}

Figure 11 shows the annual mean global cirrus and contrail cover. The mean cirrus cover computed in CAM is $40 \%$. The value depends critically on the method used and is specified here as a function of the assumed probability density function of supersaturation within each grid (Wang and Penner, 2010). The result is roughly consistent with a range of satellite observations of thin and opaque high-level clouds (Stubenrauch et al., 2013). The mean contrail cover with optical depth $\tau>0.1$ is nearly 100 times smaller: $0.50 \%$. Maximum values of up to $12 \%$ are computed for high-traffic regions in North America and Europe. The mean product
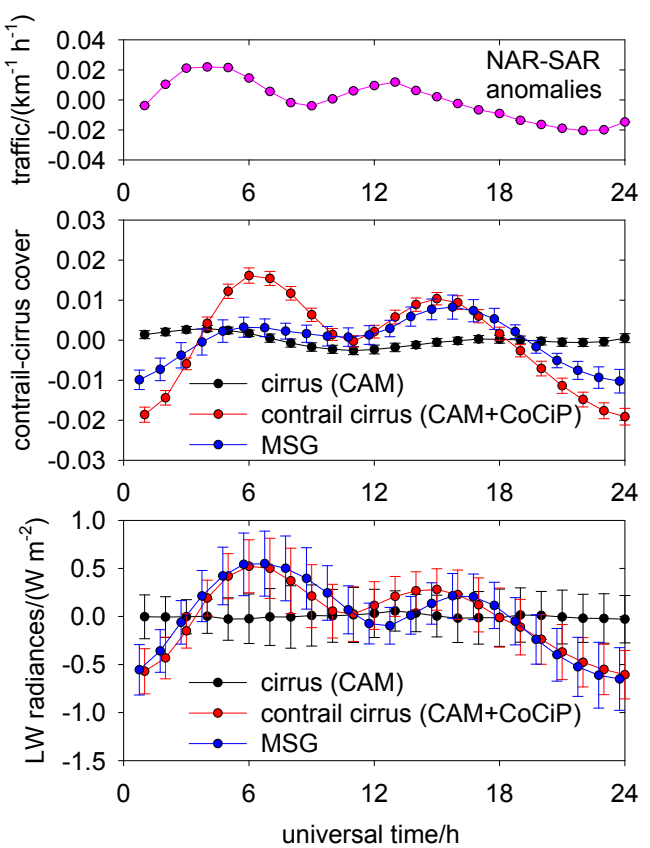

Figure 10. Diurnal cycle of anomalies of differences between a North Atlantic region and a South Atlantic region for air traffic density (top panel), cirrus cover (middle), and outgoing longwave radiation (bottom) vs. universal time of day. The error bars denote the standard deviations of annual means. In the two lower panels, black symbols denote CAM results, red symbols the sum of CAM and CoCiP contributions, and blue symbols results derived from 8 years of satellite (Meteosat second generation, MSG) infrared observations (Graf et al., 2012; Schumann and Graf, 2013).

of width $\times$ length $\times \tau$ of all individual contrail segments divided by the Earth surface area is $0.29 \%$.

The global contrail cover estimated in early assessments was below 0.1\% (Sausen et al., 1998; Penner et al., 1999). The computed contrail cover is about 5 times larger than that derived from linear contrails in satellite data (Palikonda et al., 2005; Meyer et al., 2007). More recent observation results provide higher values (Minnis et al., 2013). Burkhardt and Kärcher (2009) and Frömming et al. (2011) show that the computed contrail cover depends strongly on the assumed threshold value of optical depth used to discriminate contrails from clear sky. Rap et al. (2010b) estimated the global mean annual linear contrail coverage for air traffic of the year 2002 to be approximately $0.11 \%$. Burkhardt and Kärcher (2011) reported a contrail cirrus cover for the year 2002 of about $0.23 \%$. Schumann and Graf (2013), for the year 2006, computed a global mean cover of $0.23 \%$. The differences of the present study from previous results using $\mathrm{CoCiP}$ come mainly from the larger soot number emission index $\left(10^{15} \mathrm{~kg}^{-1}\right.$ instead of $\left.\sim 3.5 \times 10^{14} \mathrm{~kg}^{-1}\right)$. For a factor2 increase in the soot emission index, we computed increases in visible contrail cover of 1.29 , in contrail age of 1.16 , in 
a)

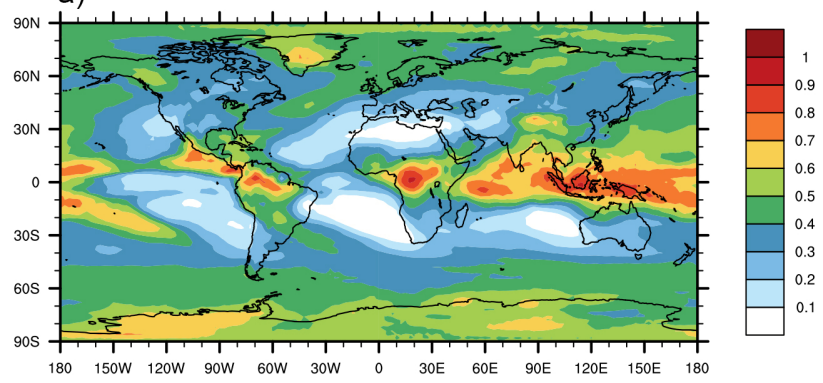

b)

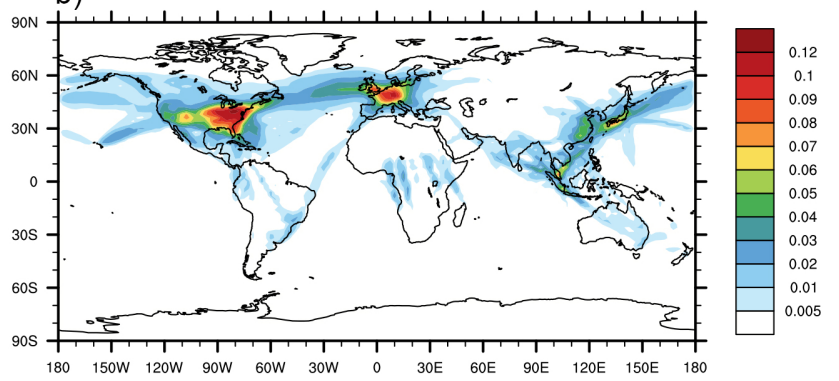

Figure 11. Panel (a): global map of annual mean cirrus cover (mean 0.40 ) and (b) cover by contrails exceeding an optical depth (at $550 \mathrm{~nm}$ ) of 0.1 (mean 0.0050$)$.

contrail width of 1.22 , in contrail geometrical depth of 1.14 , and in net contrail RF of 1.64 (Schumann et al., 2013b).

As described above, we compute contrail RF by the difference in net incoming radiative fluxes at top of the atmosphere with and without contrails. The longwave (LW) part of this $\mathrm{RF}$ is always positive and warming, the shortwave (SW) part is negative and cooling, and the net effect (sum of LW and SW RF) is often small compared to the LW forcing and may be positive or negative locally. The global RF distribution is shown in Fig. 12. The net RF reaches maximum values of more than $1 \mathrm{~W} \mathrm{~m}^{-2}$ locally over North America and Europe. The mean values are $0.584 \pm 0.045 \mathrm{~W} \mathrm{~m}^{-2}$ over central Europe $\left(10^{\circ} \mathrm{W}-20^{\circ} \mathrm{E}, 40-55^{\circ} \mathrm{N}\right)$ and $0.410 \pm 0.018 \mathrm{~W} \mathrm{~m}^{-2}$ over the continental USA $\left(65-130^{\circ} \mathrm{W}, 25-55^{\circ} \mathrm{N}\right)$. For run 1 , CoCiP computes a global mean net RF of $0.063 \mathrm{~W} \mathrm{~m}^{-2}$ (LW: $0.14 \mathrm{~W} \mathrm{~m}^{-2}$; $\mathrm{SW}:-0.08 \mathrm{~W} \mathrm{~m}^{-2}$ ). The annual mean net $\mathrm{RF}$ is positive everywhere on the globe. The global mean LW $\mathrm{RF}$ value is $12 \%$ larger than that computed by CoCiP with ECMWF data (Schumann and Graf, 2013), mainly because of the larger soot emission index.

The computed RF values are far larger than those estimated previously for linear contrails (Minnis et al., 1999; Rap et al., 2010b; Frömming et al., 2011; Yi et al., 2012; Chen and Gettelman, 2013; Spangenberg et al., 2013), 5 times larger than the value estimated for contrail cirrus for the same traffic by Chen and Gettelman (2013), and nearly double the value estimated with a global contrail cirrus model for traffic in the year 2002 by Burkhardt and Kärcher (2011).
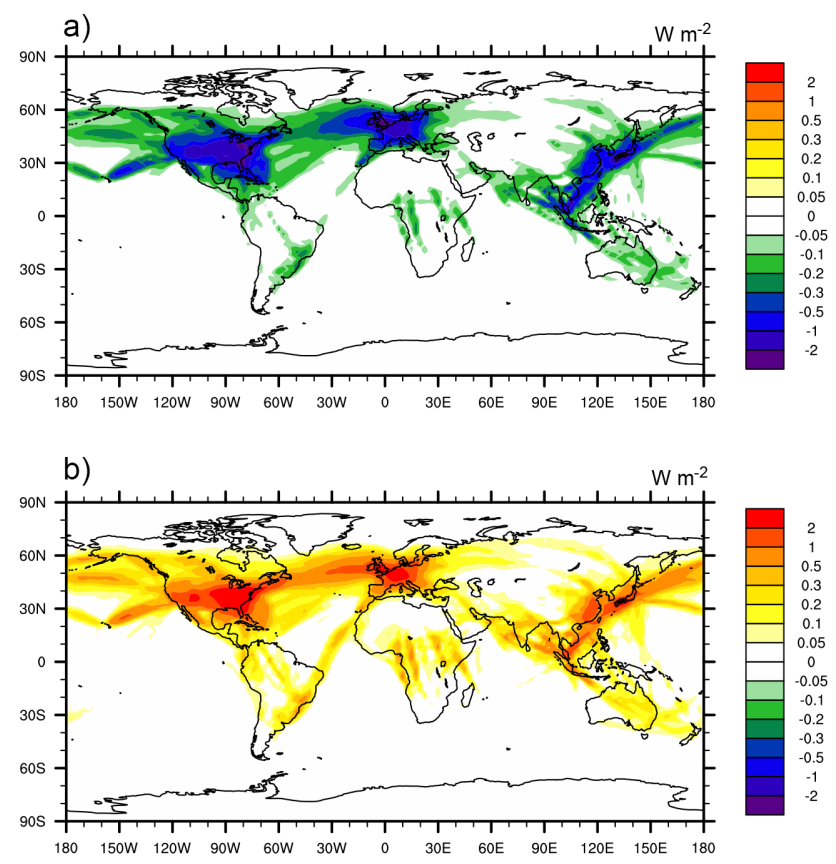

Figure 12. Global map of annual mean radiative forcing by contrails - (a) $\mathrm{SW}\left(\right.$ mean $-0.080 \mathrm{~W} \mathrm{~m}^{-2}$ ), (b) LW (mean $0.143 \mathrm{~W} \mathrm{~m}^{-2}$ ) - in logarithmic color scales.

As indicated, some of the comparisons point to possible overestimates of contrail cover and optical thickness by CoCiP. This would imply overestimates of SW and LW RF. As in previous CoCiP studies, the magnitude of the computed $\mathrm{SW} / \mathrm{LW}$ ratio is quite large (0.56). This $\mathrm{SW} / \mathrm{LW}$ ratio varies between 0.2 and 0.8 in the literature (Haywood et al., 2009; Myhre et al., 2009; Yi et al., 2012; Minnis et al., 2013; Schumann and Graf, 2013; Vázquez-Navarro et al., 2015). The ratio may become even larger for small ice particles and higher contrail temperatures (Meerkötter et al., 1999; Zhang et al., 1999). For fixed LW RF, a smaller SW / LW ratio would imply a larger net RF value. Besides, with regard to contrail lifetimes and diurnal variations, the RF values depend on the radiances without contrails, cloud temperatures, optical ice particle properties, ice water path, cloud overlap, and 3-D effects (Meerkötter et al., 1999; Markowicz and Witek, 2011; De León et al., 2012; Forster et al., 2012; Yi et al., 2012). Hence, the net RF may be both larger and smaller than $0.06 \mathrm{~W} \mathrm{~m}^{-2}$. Correct modeling of the optical properties may be more important than correct modeling of humidity exchange. Note that the reported net RF includes only the contrail effects. Contributions from dehydration in CAM are discussed below.

\subsubsection{Impact of changed background meteorology on contrail properties}

Figure 13 depicts the annual and zonal mean emissions of water from aircraft engines into the atmosphere, either 

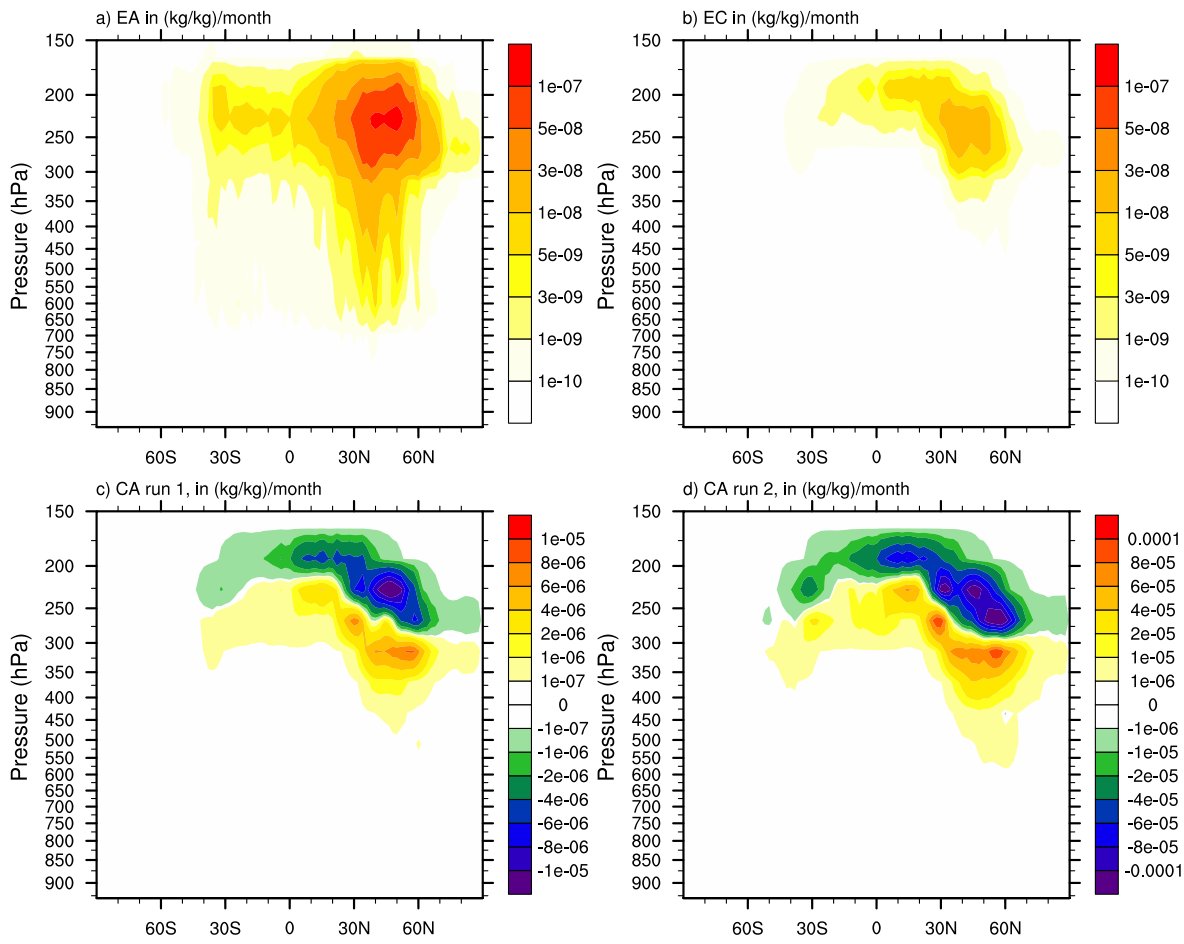

Figure 13. Zonal and annual mean water emission rates (in units of mass mixing ratio per time) vs. latitude and pressure (a) from aircraft engines directly into the free atmosphere (EA), (b) from aircraft engines into contrails (EC), and (c) from sublimating contrails into the atmosphere (CA; negative values mean water deposition on contrail ice) for run 1. Panel (d) shows CA for run 2. Note different scales.

directly (EA) or into contrails (EC). The figure also depicts the water released from contrails (CA). As explained above, the contrails take water from engine emissions and from background humidity in ice-supersaturated air masses (negative $\mathrm{CA}$ ) and release water when sublimating in subsaturated air (positive CA). Since the amount of $\mathrm{H}_{2} \mathrm{O}$ taken from ambient air is far larger than the emission, we find negative "emissions" in the CA field of $\mathrm{H}_{2} \mathrm{O}$ at flight levels and large positive values further down. The negative $\mathrm{CA}$ at flight levels in the upper troposphere implies dehydration and the positive CA lower down implies hydration contributions. For steady climate, the annual mean of $\mathrm{CA}$ becomes equal to $\mathrm{EC}$, the amount of $\mathrm{H}_{2} \mathrm{O}$ entering young contrails. Here the total budget is the result of the uptake of water by contrail minus the release, and these exchanges are far larger than the net emissions.

The $\mathrm{H}_{2} \mathrm{O}$ mass inventory in contrails amounts to $32 \mathrm{Tg}$ for run 1 , which is large; the amount corresponds to $14 \%$ of the annual aviation $\mathrm{H}_{2} \mathrm{O}$ mass emissions. The young contrails (age $<0.5 \mathrm{~h}$ ) contain $2.5 \%$ of this mass (Table 3 ). The total ice mass content in all young contrails at a given time is $7.4 \times 10^{8} \mathrm{~kg}$. Chen and Gettelman (2013) estimated this to be about $1 \times 10^{7} \mathrm{~kg}$; the large difference may explain different RF values. The mean emission altitude from engines into atmosphere $z$ is derived from an integral $z_{\mathrm{EC}}=\int z \mathrm{~d} m / \int \mathrm{d} m$, where $\mathrm{d} m$ is the local EC mass contribution. The value $z_{\mathrm{EC}}$ defines a mean contrail formation altitude. This altitude is $10.9 \mathrm{~km}$ in run 1 . The corresponding altitude of water release to the atmosphere $z_{\mathrm{CA}}$ is $700 \mathrm{~m}$ lower. For a mean contrail age of $2 \mathrm{~h}$, this corresponds to a mean fall speed of $0.1 \mathrm{~m} \mathrm{~s}^{-1}$, which appears reasonable for the particle sizes computed. Perhaps the fall time has to be added to the time of contrail formation and spreading to obtain the timescale of cirrus changes, so that the total timescale may reach half a day. This may further explain why the semidiurnal cycle in the NAR does not show up in the CAM results in Fig. 10.

Contrail formation reduces ambient humidity locally (Fig. 1) with the consequence of getting fewer or thinner contrails (Fig. 2), which are slightly longer living (Fig. 4). Contrail ice particle sedimentation brings humidity to lower levels. Even without sedimentation, contrails in subsiding air sublimate at lower levels. Contrails in rising air masses occur often because relative humidity increases from adiabatic cooling. Hence, some hydration occurs at higher levels but does not show up in the longitudinal mean values.

The effect of humidity exchange on contrails and the background atmosphere can be quantified by comparing the mean results of runs 0 and 1 (see Table 2). The contrails in the coupled model run 1 have $5 \%$ more ice particles but $29 \%$ less ice water content and a $23 \%$ smaller effective radius than in run 0 . The total $\mathrm{H}_{2} \mathrm{O}$ mass inventory changes by $39 \%$. Thus, the coupling effect is important. The contrails 


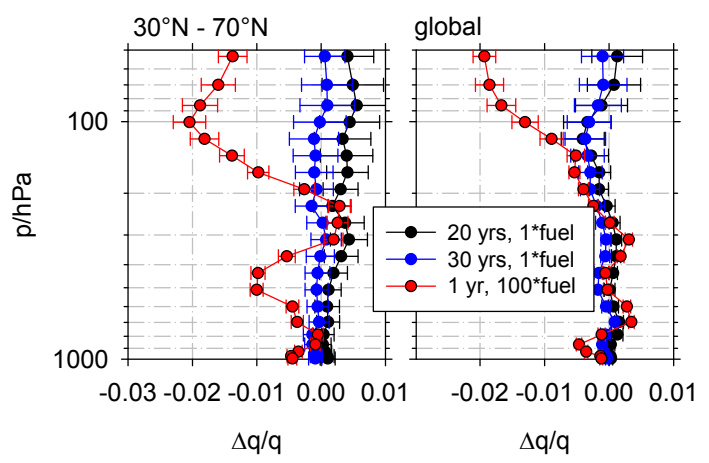

Figure 14. Vertical profiles of changes in normalized absolute humidity $(\Delta q / q)$ from differences between run 1 or 2 and run 0 averaged over 20 (black), 30 (blue), 1 (red) year(s) for the northern midlatitudes (left) and globally (right). Run 1 uses normal traffic; run 2 uses fuel consumption increased by 100 times. In this figure, error bars estimate significance limits from the root-mean-square variances divided by $\sqrt{ }(N-2)$, where $N$ is the number of years available for averaging.

have $14 \%$ lower optical depth and a $5 \%$ higher age. They live longer because the smaller ice particles sediment more slowly. The change in the net radiative forcing, from $\sim 0.07$ to $\sim 0.06 \mathrm{~W} \mathrm{~m}^{-2}$ (about $14 \%$ ), is small compared to the $\mathrm{RF}$ from contrails without dehydration.

\subsection{CAM results}

\subsubsection{Normal traffic emissions}

The redistribution of water by contrails in the atmosphere should have the strongest effects on humidity in the background atmosphere at northern midlatitudes, where most contrails form. For normal traffic, the CAM results show only small changes. The run 1-0 differences are small compared to the interannual variability in the atmosphere (see Fig. 14). In order to understand this, we estimate the order of magnitude of the source rate required to cause an appreciable change in background humidity. A background humidity mass concentration on the order of $100 \mathrm{ppm}$ and a lifetime on the order of 10 days (a 1-month lifetime cannot be excluded; Forster et al., 2003) correspond to a background humidity source on the order of $100 \mathrm{ppm} / 10 \mathrm{~d} \cong 10^{-10} \mathrm{~s}^{-1}$ or $3 \times 10^{-4}$ month $^{-1}$. In the zonal and annual mean (Fig. 12), the source rates from contrail sublimation (CA) amount to $10^{-5}$ month $^{-1}$ at most. Hence, the humidity contributions from contrails are more than a factor of 30 smaller in magnitude than natural water sources and apparently too small to be visible in 30-year climate mean values.

Radiative forcing should respond strongly to humidity and cloud changes in the troposphere and the lower stratosphere (Chen et al., 2000; Riese et al., 2012). Figure 15 shows the $\mathrm{RF}$ computed from the difference between run $1-$ run 0 . The interannual RF standard deviations are $0.2-0.3 \mathrm{~W} \mathrm{~m}^{-2}$.

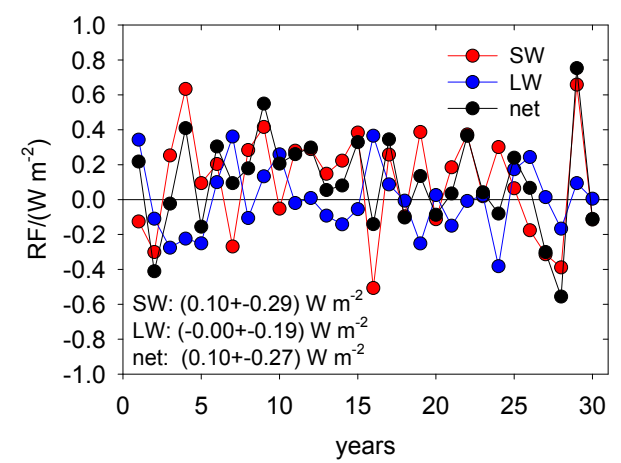

Figure 15. Annual and global mean shortwave (SW), longwave $(\mathrm{LW})$ and net $(\mathrm{SW}+\mathrm{LW})$ radiative forcing $(\mathrm{RF})$ from dehydration by contrails, as reflected in CAM by the net top-of-the-atmosphere radiance difference of run 1 - run 0 , vs. years.

The interannual changes are smaller than the variability in top-of-the-atmosphere radiances derived from satellites and from atmospheric-ocean climate models (Kato, 2009; Stephens et al., 2015) and similar to the variability in CAM5 (Zhou and Penner, 2014) but far larger than the variability $\left(<0.1 \mathrm{~W} \mathrm{~m}^{-2}\right)$ of nudged models (Chen and Gettelman, 2013). Assuming N-2 independent results from $N=30$ years of simulations, the standard error is $\sqrt{ } 28$ smaller, about $0.05 \mathrm{~W} \mathrm{~m}^{-2}$. Hence, the mean LW RF is practically 0 , and the SW and net RF values are mostly positive but only weakly significant. A positive net RF could not be explained with reduced cirrus clouds (Burkhardt and Kärcher, 2011).

The annual mean RF values vary from year to year and show significant correlations with other annual and global mean diagnostics from CAM. Figure 16 shows strong correlations of RF with liquid water path and with low-level cloud cover. For SW RF, the correlation with low cloud cover is stronger than with high-level cloud cover. Hence, the interannual variability in RF appears to be linked mainly to the variability in low-level cloudiness.

\subsubsection{Enhanced traffic emissions}

In order to increase the signal-to-noise ratio in the CAM simulations, we consider run 2 with traffic emissions 100 times enhanced. The increased traffic emissions are implemented in CoCiP using the same number of flights but fuel consumption 100 times larger, implying water mass and soot number emissions 100 times larger. This causes large changes in the contrail properties (see Table 4). We see a number of ice particles per unit length that is 94 times larger and an ice particle number volume concentration that 6 times larger but $60 \%$ less specific ice water content. Hence, as expected, e.g., from Unterstrasser and Gierens (2010a), the increased soot emission causes far more contrail ice particles, while the enhanced water emissions are less important. Moreover, CoCiP computes a doubled mean contrail lifetime, an optical depth 
Table 4. Change in contrail properties for fuel consumption 100 times larger.

\begin{tabular}{|c|c|c|c|}
\hline Parameter & $\begin{array}{l}\text { Run } 1 \\
\text { online }\end{array}$ & $\begin{array}{r}\text { Run } 2 \\
100 \times \text { fuel }\end{array}$ & $\begin{array}{r}\text { Ratio } \\
\text { runs } 2 / 1\end{array}$ \\
\hline Fuel consumption in contrails $\left(\mathrm{kg} \mathrm{km}^{-1}\right)$ & 5.33 & 533 & 100 \\
\hline Ice crystals $\left(10^{12} \mathrm{~m}^{-1}\right)$ & 2.87 & 272 & 94 \\
\hline Total ice mass inventory $(\mathrm{Tg})$ & 31.8 & 311 & 9.8 \\
\hline Sedimentation distance $(\mathrm{m})$ & 0.734 & 0.735 & 1.0 \\
\hline Age $(h)$ & 2.00 & 4.02 & 2.0 \\
\hline Width $(\mathrm{km})$ & 18.1 & 168 & 9.3 \\
\hline Effective depth (m) & 829 & 2380 & 2.9 \\
\hline $\operatorname{IWC}\left(\mathrm{mg} \mathrm{m}^{-3}\right)$ & 7.5 & 3.1 & 0.42 \\
\hline Ice particle number concentration $\left(\mathrm{cm}^{-3}\right)$ & 0.438 & 2.70 & 6.2 \\
\hline Effective radius $(\mu \mathrm{m})$ & 35.1 & 13.0 & 0.37 \\
\hline Ice mass content $\left(\mathrm{kg} \mathrm{m}^{-1}\right)$ & 138 & 155 & 1.1 \\
\hline Ice mass content per $\mathrm{H}_{2} \mathrm{O}$ emission (1) & 21100 & 2350 & 0.11 \\
\hline Contrail net $\mathrm{RF}\left(\mathrm{W} \mathrm{m}^{-2}\right)$ & 0.063 & 0.87 & 13.81 \\
\hline Cover of contrails with $\tau>0.1(\%)$ & 0.505 & 3.88 & 7.68 \\
\hline Optical depth of contrails with $\tau>0.1$ (1) & 0.367 & 1.375 & 3.75 \\
\hline
\end{tabular}
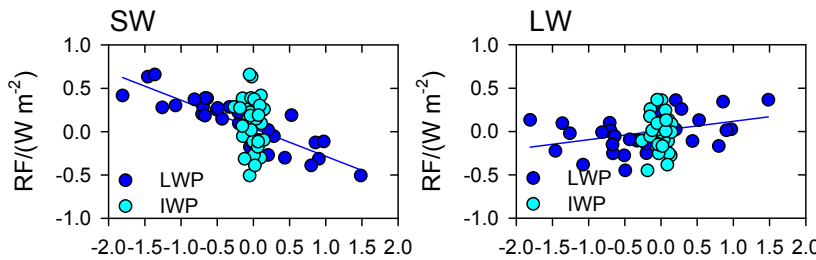

LWP, IWP/(g m $\left.{ }^{-2}\right)$
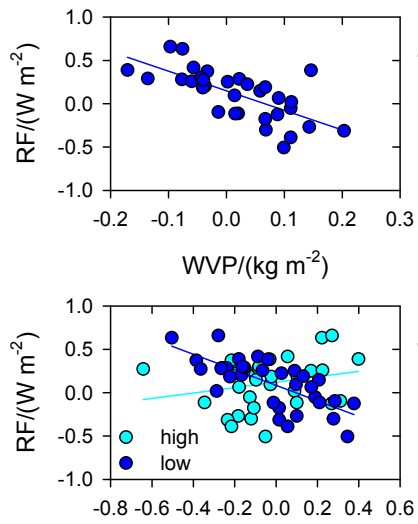

cloud cover $/ \%$
LWP, IWP/( $\left.\mathrm{g} \mathrm{m}^{-2}\right)$
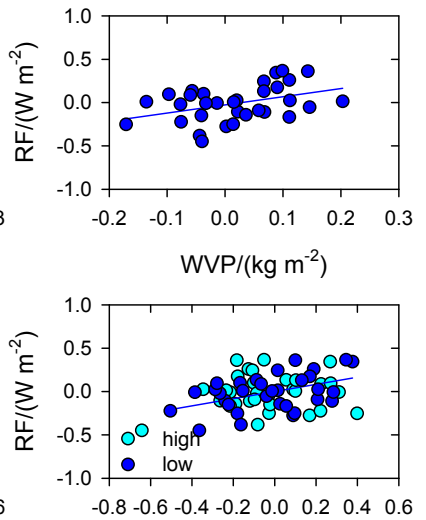

cloud cover $/ \%$
Figure 16. SW (left panels) and LW (right) RF correlations with liquid and ice water path (LWP, IWP), water vapor path (WVP), and high- and low-level cloud cover in annual mean values of the differences of CAM results in run 1 and run 0 .

4 times larger, and 8 times more contrail cover, and about a net contrail RF 14 times larger.

CAM does not see the soot but sees changes in water emissions CA (with a small contribution from EA). CoCiP computes a contrail ice water mass inventory that is about 10 times larger and about the same sedimentation depth. Fig- ure 13 (lower panels) shows the distributions of the effective emissions CA for runs 1 and 2. We find similar distributions with CA values about 10 times larger in run 2 . The ratios of the maximum, minimum, and global mean rms values of CA in runs 2 and 1 are 12.4, 9.8 and 12.9, respectively. Hence, the water inventory, the exchange between contrails and the background atmosphere in run 2 are about 10 times larger than in run 1.

Figure 14 shows that the mean humidity profile responds to the larger water exchange significantly. The contrails cause global dehydration mainly of the tropopause region (including the lower stratosphere) and a local increase in humidity in the mid-troposphere below the main flight levels at northern midlatitudes. The global mean humidity decreases. Hence, the redistribution of humidity by contrails changes the entire hydrological cycle.

Figure 17 plots the RF of dehydration derived by CAM from run 1-0 differences as a function of the contrail ice water inventory, which is used as a measure of the change in water exchange CA. The mean values are compared in Table 5 . For run 2, the RF values are computed from the 1-year mean of run 2 and 30 annual mean values of run 0 . The standard deviation from 30 years of run 2 might be a factor of $\sqrt{ } 2$ larger.

The mean SW and LW RF results are significant at the $95 \%$ confidence level for enhanced fuel consumption. SW $\mathrm{RF}$ is positive in this case, suggesting that dehydration reduces cloud cover, both in the upper and lower troposphere, causing lower Earth albedo and, hence, warming the atmosphere. LW RF is negative (cooling), which would be consistent with reduced cloud cover and reduced water vapor in the cold tropopause region. The net RF values are small and have different signs in runs 1 and 2 . 
Table 5. Annual and global mean CAM results for normal (run 1) and $100 \times$ fuel (run 2), with standard deviations of interannual variability $(\sigma)$.

\begin{tabular}{llrrrrl}
\hline Abbreviation & Parameter & $\begin{array}{r}\text { Run 1, } \\
\text { mean }\end{array}$ & $\pm \sigma$ & $\begin{array}{r}\text { Run 2, } \\
\text { mean }\end{array}$ & $\pm \sigma$ & Unit \\
\hline FSNT & SW net RF & 0.077 & 0.301 & 0.272 & 0.190 & $\mathrm{~W} \mathrm{~m}^{-2}$ \\
FLNT & LW net RF & -0.007 & 0.181 & -0.449 & 0.130 & $\mathrm{~W} \mathrm{~m}^{-2}$ \\
SWCF & SW cloud forcing & 0.076 & 0.320 & 0.313 & 0.204 & $\mathrm{~W} \mathrm{~m}^{-2}$ \\
LWCF & LW cloud forcing & -0.017 & 0.132 & -0.211 & 0.094 & $\mathrm{~W} \mathrm{~m}^{-2}$ \\
FSNTC & SW clear-sky forcing & 0.002 & 0.092 & -0.042 & 0.062 & $\mathrm{~W} \mathrm{~m}^{-2}$ \\
FLNTC & LW clear-sky forcing & 0.010 & 0.112 & -0.239 & 0.081 & $\mathrm{~W} \mathrm{~m}^{-2}$ \\
LWP & liquid water path & -0.201 & 0.778 & -0.494 & 0.526 & $\mathrm{~g} \mathrm{~m}^{-2}$ \\
IWP & ice water path & -0.001 & 0.096 & -0.186 & 0.071 & $\mathrm{~g} \mathrm{~m}^{-2}$ \\
WVM & water vapor path & 0.011 & 0.086 & -0.040 & 0.067 & $\mathrm{~kg} \mathrm{~m}^{-2}$ \\
CLDHGH & high-level cloud cover & -0.033 & 0.201 & -0.642 & 0.103 & $\%$ \\
CLDMED & mid-level cloud clover & -0.037 & 0.150 & -0.241 & 0.123 & $\%$ \\
CLDLOW & low-level cloud cover & -0.024 & 0.201 & -0.365 & 0.131 & $\%$ \\
\hline
\end{tabular}

Table 5 shows that dehydration by contrails causes significant changes in CAM mean values for enhanced emissions. We find reduced cloud cover and a reduced water path in all phases. All of these changes are consistent with a causal impact of humidity redistribution by contrails on the hydrological cycle. The results suggest that ice particles sedimenting from contrails transport humidity downwards causing low-level cloud changes. The added humidity at lower levels may enhance liquid water content and cloud droplet sizes and, hence, precipitation. The available diagnostics do not allow us to quantify how much the Wegener-FindeisenBergeron process contributes to ice particle growth from evaporating cloud droplets, thereby enhancing precipitation.

Low-level cloud changes by aviation aerosol have been found before (Righi et al., 2013), but such effects from dehydration have not been reported before. The SW plus LW clear-sky RF (see Table 5), mainly from the reduced water vapor path, is of opposite sign and far larger in magnitude than the RF from aviation water emissions without contrail formation (about $0.001 \mathrm{~W} \mathrm{~m}^{-2}$; Wilcox et al., 2012), even when scaling the run-2 values by factors of 10 to 100 .

Interpolating linearly in the ice mass inventories (Fig. 17) suggests that the magnitudes of the SW and LW RF components of the dehydration effects for nominal traffic are about $0.04 \mathrm{~W} \mathrm{~m}^{-2}$. Because of the different signs of the $\mathrm{SW}$ and $\mathrm{LW}$ contributions, the net RF from dehydration is smaller, and not much different from the $-0.007 \mathrm{~W} \mathrm{~m}^{-2}$ result estimated by Burkhardt and Kärcher (2011). Hence, the dehydration may reduce the RF from contrails, but only slightly. Our best estimate for the total net RF stays within the range of 0.04-0.08 $\mathrm{W} \mathrm{m}^{-2}$ estimated earlier (Schumann and Graf, 2013).

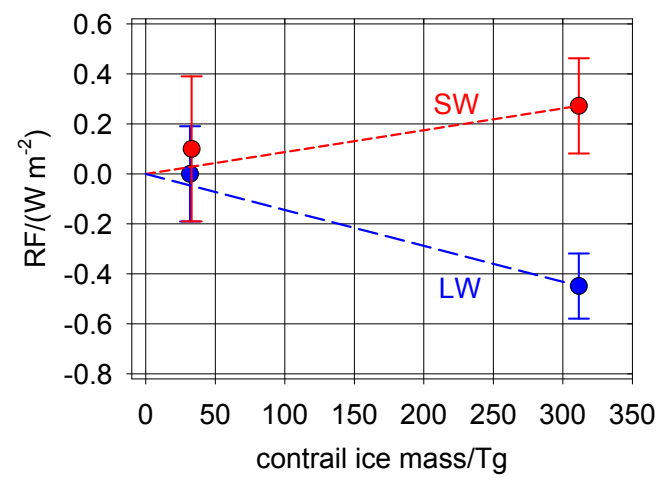

Figure 17. SW and LW RF from humidity redistribution by contrails in CAM for nominal (run 1 - run 0) or air traffic emissions increased by 100 times (run 2 - run 0 ) as a function of global ice mass in contrails. The error bars denote the standard deviations of interannual fluctuations; for run 2 these are computed from 30 years of run 0 and 1 year of run 2 results. The red and blue lines indicate linear interpolations between zero and the RF results computed in run 2 for increased air traffic.

\section{Conclusions}

This paper studied the effects of contrails from aviation on the redistribution of humidity in the atmosphere. For this purpose, we coupled the contrail model CoCiP with the climate model CAM3+-IMPACT (CAM). The contrail model simulates all the individual contrails forming from global air traffic for meteorological conditions as defined by the climate model. The climate model simulates aerosol-cloud processes in the global atmosphere. The coupled model simulates the exchange of humidity between background atmosphere and contrails and the resultant changes in the atmosphere, including cloudiness and the atmospheric part of the hydrological cycle. The results are from two major model runs with and without contrail water exchange, running hourly over 
30 years. In addition, the coupled model was run with enhanced air traffic emissions for 1 year.

The major findings are as follows:

- The mean contrail ensemble properties are as expected from the present understanding and are consistent with available observations.

- The computed optical depth values are close to those observed by lidar and satellites from space.

- In agreement with previous studies, the optical bulk properties of the contrails are strongly linked to ice particle sedimentation in ice-supersaturated air.

- In the coupled model, contrail water content may be $10^{3}$ to $10^{6}$ times larger than the amount of $\mathrm{H}_{2} \mathrm{O}$ emitted. On average, about 3000 contrail segments are active at any time.

- Contrail growth causes dehydration at flight levels; the large ice particles sediment, on average by $700 \mathrm{~m}$, eventually sublimate and hydrate the atmosphere at lower levels. In rising air masses, hydration occurs locally at higher levels.

- The drying at flight levels changes mean contrail properties by +5 to $-30 \%$ : contrails become thinner and have a higher mean age. Net contrail RF is reduced by $\sim 15 \%$ from $\sim 0.07$ to $\sim 0.06 \mathrm{~W} \mathrm{~m}^{-2}$.

- The model simulates a diurnal cycle of cirrus properties in the North Atlantic, which reflects the diurnal cycle of air traffic in that region and which is close to the cycle observed by satellites. Dehydration-driven diurnalcycle cirrus changes in the global model were not detectable.

- The total dehydration RF is too small to be computed for nominal emissions because of climate noise in the freely running atmosphere climate model (interannual RF standard deviations about $0.2 \mathrm{~W} \mathrm{~m}^{-2}$ ).

- Increasing the fuel consumption by 100 shows significant changes. The contrails respond strongly to the increases in soot emissions, causing a larger ice mass inventory in contrails and stronger water exchange between contrails and the background atmosphere. The larger contrail water exchange drives significant mean dehydration effects in the global atmosphere.

- Based on these simulations, the redistribution of water by contrails causes negative LW RF because of reduced humidity near the tropopause (opposite sign and far larger than RF from aviation water emissions without contrails) and positive SW from reduced cloud cover, with magnitudes for normal traffic likely less than $\pm 0.04 \mathrm{~W} \mathrm{~m}^{-2}$. The net dehydration effect is estimated to be about $-0.01 \mathrm{~W} \mathrm{~m}^{-2}$. The sum of contrail and dehydration net RF stays within the range of 0.04 $0.08 \mathrm{~W} \mathrm{~m}^{-2}$ derived for contrail cirrus from earlier studies.

- In the global model, dehydration impacts the entire hydrological system, including high- and low-level clouds. Both liquid and ice water paths and cloud cover of lowand high-level clouds are reduced.

The quantitative results are sensitive to model details. For example, the sedimentation is only crudely simulated with CoCiP because the details depend on the particle size spectrum, which is not resolved in CoCiP. Possibly, the simulated contrails are slightly thicker than expected from the observations. Thinner contrails would appear, e.g., for a smaller effective soot emission index. As a whole, the comparisons with observations show that the coupled model provides results in reasonable agreement with observations. This is a positive indicator not only for the quality of $\mathrm{CoCiP}$ but also the quality of the input fields provided by CAM, in particular with respect to ice supersaturation, which is crucial to the prediction of long-lived contrails.

This paper discussed the effects of water exchange between contrails and ambient air. Aircraft aerosols from aircraft engines emissions, possibly changed in contrails, may also impact the entire hydrological cycle and could be studied with an extension of this model in the future.

Author contributions. J. E. Penner and U. Schumann designed the research and wrote the paper. U. Schumann, Y. Chen, C. Zhou, and $\mathrm{K}$. Graf coded the programs and data analysis and discussed the results.

Acknowledgements. This research was supported by the Federal Aviation Administration (FAA) within the ACCRI project, and by DLR within the DLR projects CATS and WeCare. J. E. Penner, Y. Chen and $\mathrm{C}$. Zhou also acknowledge funding from the National Science Foundation (NSF). Computing resources (ark:/85065/d7wd3xhc) were provided by the Climate Simulation Laboratory at NCAR's Computational and Information Systems Laboratory, sponsored by the NSF and other agencies.

The article processing charges for this open-access publication were covered by a Research

Centre of the Helmholtz Association.

Edited by: B. Vogel

\section{References}

Atlas, D., Wang, Z., and Duda, D. P.: Contrails to cirrus - morphology, microphysics, and radiative properties, J. Appl. Meteorol. Clim., 45, 5-19, doi:10.1175/JAM2325.1, 2006. 
Bedka, S. T., Minnis, P., Duda, D. P., Chee, T. L., and Palikonda, R.: Properties of linear contrails in the Northern Hemisphere derived from 2006 Aqua MODIS observations, Geophys. Res. Lett., 40, 772-777, doi:10.1029/2012GL054363, 2013.

Boucher, O., Randall, D., Artaxo, P., Bretherton, C., Feingold, G., Forster, P., Kerminen, V.-M., Kondo, Y., Liao, H., Lohmann, U., Rasch, P., Satheesh, S. K., Sherwood, S., Stevens, B., and Zhang, X. Y.: Clouds and aerosols, in: Climate Change 2013: The Physical Science Basis. Contribution of Working Group I to the Fifth Assessment Report of the Intergovernmental Panel on Climate Change, edited by: Stocker, T., Qin, F. D., Plattner, G.K., Tignor, M., Allen, S. K., Boschung, J., Nauels, A., Xia, Y., Bex, V., and Midgley, P. M., Cambridge University Press, Cambridge, UK and New York, NY, USA, 571-657, 2013.

Brasseur, G. P., Cox, R. A., Hauglustaine, D., Isaksen, I., Lelieveld, J., Lister, D. H., Sausen, R., Schumann, U., Wahner, A., and Wiesen, P.: European scientific assessment of the atmospheric effects of aircraft emissions, Atmos. Environ., 32, 2329-2418, 1998.

Brasseur, G. P., Gupta, M., Anderson, B. E., Balasubramanian, S., Barrett, S., Duda, D., Fleming, G., Forster, P. M., Fuglestvedt, J., Gettelman, A., Halthore, R. N., Jacob, S. D., Jacobson, M. C., Khodayari, A., Liou, K.-N., Lund, M. T., Miake-Lye, R. C., Minnis, P., Olsen, S. C., Penner, J. E., Prinn, R., Schumann, U., Selkirk, H. B., Sokolov, A., Unger, N., Wolfe, P., Wong, H.W., Wuebbles, D. W., Yi, B., Yang, P., and Zhou, C.: Impact of aviation on climate: FAA's Aviation Climate Change Research Initiative (ACCRI) Phase II, B. Am. Meteorol. Soc., doi:10.1175/BAMS-D-13-00089.1, online first, 2015.

Burkhardt, U. and Kärcher, B.: Process-based simulation of contrail cirrus in a global climate model, J. Geophys. Res., 114, 1-13, doi:10.1029/2008JD011491, 2009.

Burkhardt, U. and Kärcher, B.: Global radiative forcing from contrail cirrus, Nature Clim. Change, 1, 54-58, doi:10.1038/NCLIMATE1068, 2011.

Burkhardt, U., Kärcher, B., and Schumann, U.: Global modelling of the contrail and contrail cirrus climate impact, B. Am. Meteorol. Soc., 91, 479-484, doi:10.1175/2009BAMS2656.1, 2010.

Chen, C.-C. and Gettelman, A.: Simulated radiative forcing from contrails and contrail cirrus, Atmos. Chem. Phys., 13, 1252512536, doi:10.5194/acp-13-12525-2013, 2013.

Chen, T., Rossow, W. B., and Zhang, Y. C.: Radiative effects of cloud-type variations, J. Climate, 13, 264-286, 2000.

De León, R. R., Krämer, M., Lee, D. S., and Thelen, J. C.: Sensitivity of radiative properties of persistent contrails to the ice water path, Atmos. Chem. Phys., 12, 7893-7901, doi:10.5194/acp-127893-2012, 2012.

Ewald, F., Bugliaro, L., Mannstein, H., and Mayer, B.: An improved cirrus detection algorithm MeCiDA2 for SEVIRI and its evaluation with MODIS, Atmos. Meas. Tech., 6, 309-322, doi:10.5194/amt-6-309-2013, 2013.

Fahey, D. W. and Schumann, U.: Aviation-produced aerosols and cloudiness, in: Aviation and the Global Atmosphere. A Special Report of IPCC Working Groups I and III, edited by: Penner, J. E., Lister, D. H., Griggs, D. J., Dokken, D. J., and McFarland, M., Cambridge University Press, New York, 65-120, 1999.

Forster, C., Stohl, A., James, P., and Thouret, V.: The residence times of aircraft emissions in the stratosphere using a mean emis- sion inventory and emissions along actual flight tracks, J. Geophys. Res., 108, 8524, doi:10.1029/2002JD002515, 2003.

Forster, L., Emde, C., Unterstrasser, S., and Mayer, B.: Effects of three-dimensional photon transport on the radiative forcing of realistic contrails, J. Atmos. Sci., 69, 2243-2255, doi:10.1175/JAS-D-11-0206.1, 2012.

Frömming, C., Ponater, M., Burkhardt, U., Stenke, A., Pechtl, S., and Sausen, R.: Sensitivity of contrail coverage and contrail radiative forcing to selected key parameters, Atmos. Environ., 45, 1483-1490, doi:10.1016/j.atmosenv.2010.11.033, 2011.

Fueglistaler, S., Dessler, A. E., Dunkerton, T. J., Folkins, I., Fu, Q., and Mote, P. W.: Tropical tropopause layer, Rev. Geophys., 47, RG1004, doi:10.1029/2008RG000267, 2009.

Fusina, F., Spichtinger, P., and Lohmann, U.: Impact of ice supersaturated regions and thin cirrus on radiation in the midlatitudes, J. Geophys. Res., 112, D24S14, doi:10.1029/2007JD008449, 2007.

Gettelman, A. and Chen, C.: The climate impact of aviation aerosols, Geophys. Res. Lett., 40, 2785-2789, doi:10.1002/grl.50520, 2013.

Graf, K., Schumann, U., Mannstein, H., and Mayer, B.: Aviation induced diurnal North Atlantic cirrus cover cycle, Geophys. Res. Lett., 39, L16804, doi:10.1029/2012GL052590, 2012.

Haywood, J. M., Allan, R. P., Bornemann, J., Forster, P. M., Francis, P. N., Milton, S., Rädel, G., Rap, A., Shine, K. P., and Thorpe, R.: A case study of the radiative forcing of persistent contrails evolving into contrail-induced cirrus, J. Geophys. Res., 114, D24201, doi:10.1029/2009JD012650, 2009.

Hendricks, J., Kärcher, B., and Lohmann, U.: Effects of ice nuclei on cirrus clouds in a global climate model, J. Geophys. Res., 116, D18206, doi:10.1029/2010JD015302, 2011.

Heymsfield, A., Baumgardner, D., DeMott, P., Forster, P., Gierens, K., and Kärcher, B.: Contrail microphysics, B. Am. Meteorol. Soc., 90, 465-472, doi:10.1175/2009BAMS2839.1, 2010.

Heymsfield, A. J., Lawson, R. P., and Sachse, G. W.: Growth of ice crystals in a precipitating contrail, Geophys. Res. Lett., 25, 1335-1338, doi:10.1029/98GL00189, 1998.

Immler, F., Treffeisen, R., Engelbart, D., Krüger, K., and Schrems, O.: Cirrus, contrails, and ice supersaturated regions in high pressure systems at northern mid latitudes, Atmos. Chem. Phys., 8, 1689-1699, doi:10.5194/acp-8-1689-2008, 2008.

Iwabuchi, H., Yang, P., Liou, K. N., and Minnis, P.: Physical and optical properties of persistent contrails: Climatology and interpretation, J. Geophys. Res., 117, D06215, doi:10.1029/2011JD017020, 2012.

Jensen, E. J., Toon, O. B., Pfister, L., and Selkirk, H. B.: Dehydration of the upper troposphere and lower stratosphere by subvisible cirrus clouds near the tropical tropopause, Geophys. Res. Lett., 23, 825-828, doi:10.1029/96GL00722, 1996.

Jensen, E. J., Ackermann, A. S., Stevens, D. E., Toon, O. B., and Minnis, P.: Spreading and growth of contrails in a sheared environment, J. Geophys. Res., 103, 31557-31567, doi:10.1029/98JD02594, 1998.

Jeßberger, P., Voigt, C., Schumann, U., Sölch, I., Schlager, H., Kaufmann, S., Petzold, A., Schäuble, D., and Gayet, J.-F.: Aircraft type influence on contrail properties, Atmos. Chem. Phys., 13, 11965-11984, doi:10.5194/acp-13-11965-2013, 2013. 
Kärcher, B. and Burkhardt, U.: Effects of optical depth variability on contrail radiative forcing, Q. J. Roy. Meteor. Soc., 139, 16581664, doi:10.1002/qj.2053, 2013.

Kato, S.: Interannual variability of the global radiation budget, J. Climate, 22, 4893-4907, doi:10.1175/2009JCLI2795.1, 2009.

Kaufmann, S., Voigt, C., Jeßberger, P., Jurkat, T., Schlager, H., Schwarzenboeck, A., Klingebiel, M., and Thornberry, T.: In-situ measurements of ice saturation in young contrails, Geophys. Res. Lett., 41, 702-709, doi:10.1002/2013GL058276, 2014.

Kienast-Sjögren, E., Spichtinger, P., and Gierens, K.: Formulation and test of an ice aggregation scheme for two-moment bulk microphysics schemes, Atmos. Chem. Phys., 13, 9021-9037, doi:10.5194/acp-13-9021-2013, 2013.

Knollenberg, R. G.: Measurements of the growth of the ice budget in a persisting contrail, J. Atmos. Sci., 29, 1367-1374, 1972.

Korolev, A. and Mazin, I. P.: Supersaturation of water vapor in clouds, J. Atmos. Sci., 60, 2957-2974, 2003.

Kübbeler, M., Hildebrandt, M., Meyer, J., Schiller, C., Hamburger, Th., Jurkat, T., Minikin, A., Petzold, A., Rautenhaus, M., Schlager, H., Schumann, U., Voigt, C., Spichtinger, P., Gayet, J.F., Gourbeyre, C., and Krämer, M.: Thin and subvisible cirrus and contrails in a subsaturated environment, Atmos. Chem. Phys., 11, 5853-5865, doi:10.5194/acp-11-5853-2011, 2011.

Lee, D. S., Fahey, D. W., Forster, P. M., Newton, P. J., Wit, R. C. N., Lim, L. L., Owen, B., and Sausen, R.: Aviation and global climate change in the 21st century, Atmos. Environ., 43, 35203537, doi:10.1016/j.atmosenv.2009.04.024, 2009.

Lee, D. S., Pitari, G., Grewe, V., Gierens, K., Penner, J. E., Petzold, A., Prather, M. J., Schumann, U., Bais, A., Berntsen, T., Iachetti, D., Lim, L. L., and Sausen, R.: Transport impacts on atmosphere and climate: aviation, Atmos. Environ., 44, 46784734, doi:10.1016/j.atmosenv.2009.06.005, 2010.

Lewellen, D. C.: Persistent contrails and contrail cirrus. Part II: Full lifetime behavior, J. Atmos. Sci., 71, 4420-4438, doi:10.1175/JAS-D-13-0317.1, 2014.

Lewellen, D. C. and Lewellen, W. S.: The effects of aircraft wake dynamics on contrail development, J. Atmos. Sci., 58, 390-406, 2001.

Lewellen, D. C., Meza, O., and Huebsch, W. W.: Persistent contrails and contrail cirrus. Part I: Large-eddy simulations from inception to demise, J. Atmos. Sci., 70, 4399-4419, doi:10.1175/JAS-D13-0316.1, 2014.

Liu, X., Penner, J. E., Ghan, S. J., and Wang, M.: Inclusion of ice microphysics in the NCAR Community Atmosphere Model version 3 (CAM3), J. Climate, 20, 4526-4547, doi:10.1175/JCLI4264.1, 2007.

Mannstein, H. and Schumann, U.: Aircraft induced contrail cirrus over Europe, Meteorol. Z., 14, 549-554, doi:10.1127/09412948/2005/0058, 2005.

Markowicz, K. M. and Witek, M.: Sensitivity study of global contrail radiative forcing due to particle shape, J. Geophys. Res., 116, D23203, doi:10.1029/2011JD016345, 2011.

McFarquhar, G. M. and Heymsfield, A. J.: The definition and significance of an effective radius for ice clouds, J. Atmos. Sci., 55, 2039-2052, 1998.

Meerkötter, R., Schumann, U., Minnis, P., Doelling, D. R., Nakajima, T., and Tsushima, Y.: Radiative forcing by contrails, Ann. Geophys., 17, 1080-1094, doi:10.1007/s00585-999-10807, 1999.
Meyer, R., Buell, R., Leiter, C., Mannstein, H., Pechtl, S., Oki, T., and Wendling, P.: Contrail observations over southern and eastern Asia in NOAA/AVHRR data and comparisons to contrail simulations in a GCM, Int. J. Remote Sens., 28, 2049-2069, doi:10.1080/01431160600641707, 2007.

Minnis, P., Young, D. F., Garber, D. P., Nguyen, L., Smith Jr., W. L., and Palikonda, R.: Transformation of contrails into cirrus during SUCCESS, Geophys. Res. Lett., 25, 1157-1160, doi:10.1029/97GL03314, 1998.

Minnis, P., Schumann, U., Doelling, D. R., Gierens, K., and Fahey, D. W.: Global distribution of contrail radiative forcing, Geophys. Res. Lett., 26, 1853-1856, doi:10.1029/1999GL900358, 1999.

Minnis, P., Bedka, S. T., Duda, D. P., Bedka, K. M., Chee, T., Ayers, J. K., Palikonda, R., Spangenberg, D. A., Khlopenkov, K. V., and Boeke, R.: Linear contrail and contrail cirrus properties determined from satellite data, Geophys. Res. Lett., 40, 3220-3226, doi:10.1002/grl.50569, 2013.

Murcray, W. B.: On the possibility of weather modification by aircraft contrails, Mon. Weather Rev., 98, 745-748, doi:10.1175/1520-0493(1970)098<0745:OTPOWM>2.3.CO;2, 1970.

Myhre, G., Kvalevag, M., Rädel, G., Cook, J., Shine, K. P., Clark, H., Karcher, F., Markowicz, K., Karda, A., Wolkenberg, O., Balkanski, Y., Ponater, M., Forster, P., Rap, A., and Rodriguez de Leon, R.: Intercomparison of radiative forcing calculations of stratospheric water vapour and contrails, Meteorol. Z., 18, 585-596, doi:10.1127/0941-2948/2009/0411, 2009.

Naiman, A. D., Lele, S. K., and Jacobson, M. Z.: Large eddy simulations of contrail development: sensitivity to initial and ambient conditions over first twenty minutes, J. Geophys. Res., 116, D21208, doi:10.1029/2011JD015806, 2011.

Palikonda, R., Minnis, P., Duda, D. P., and Mannstein, H.: Contrail coverage derived from 2001 AVHRR data over the continental United States of America and surrounding areas, Meteorol. Z., 14, 525-536, doi:10.1127/0941-2948/2005/0051, 2005.

Pauluis, O., Czaja, A., and Korty, R.: The global atmospheric circulation on moist isentropes, Science, 321, 1075-1078, 2008.

Penner, J. E., Lister, D. H., Griggs, D. J., Dokken, D. J., and McFarland, M.: Aviation and the Global Atmosphere - a Special Report of IPCC Working Groups I and III, Intergovernmental Panel on Climate Change, Cambridge University Press, 365 pp., 1999.

Penner, J. E., Chen, Y., Wang, M., and Liu, X.: Possible influence of anthropogenic aerosols on cirrus clouds and anthropogenic forcing, Atmos. Chem. Phys., 9, 879-896, doi:10.5194/acp-9-8792009, 2009.

Ponater, M., Marquart, S., Sausen, R., and Schumann, U.: On contrail climate sensitivity, Geophys. Res. Lett., 32, L10706, doi:10.1029/2005gl022580, 2005.

Rap, A., Forster, P. M., Haywood, J. M., Jones, A., and Boucher, O.: Estimating the climate impact of linear contrails using the UK Met Office climate model, Geophys. Res. Lett., 37, L20703, doi:10.1029/2010GL045161, 2010a.

Rap, A., Forster, P. M., Jones, A., Boucher, O., Haywood, J. M., Bellouin, N., and Leon, R. R. D.: Parameterization of contrails in the UK Met Office Climate Model, J. Geophys. Res., 115, D10205, doi:10.1029/2009JD012443, 2010b.

Riese, M., Ploeger, F., Rap, A., Vogel, B., Konopka, P., Dameris, M., and Forster, P.: Impact of uncertainties in atmospheric mixing 
on simulated UTLS composition and related radiative effects, J. Geophys. Res., 117, D16305, doi:10.1029/2012JD017751, 2012.

Righi, M., Hendricks, J., and Sausen, R.: The global impact of the transport sectors on atmospheric aerosol: simulations for year 2000 emissions, Atmos. Chem. Phys., 13, 9939-9970, doi:10.5194/acp-13-9939-2013, 2013.

Sausen, R., Gierens, K., Ponater, M., and Schumann, U.: A diagnostic study of the global distribution of contrails. Part I: Present day climate, Theor. Appl. Climatol., 61, 127-141, doi:10.1007/s007040050058, 1998.

Sausen, R., Isaksen, I., Hauglustaine, D., Grewe, V., Lee, D. S., Myhre, G., Köhler, M. O., Pitari, G., Schumann, U., Stordal, F., and Zerefos, C.: Aviation radiative forcing in 2000: an update on IPCC: 1999, Meteorol. Z., 14, 555-561, doi:10.1127/09412948/2005/0049, 2005.

Schiller, C., Krämer, M., Afchine, A., Spelten, N., and Sitnikov, N.: Ice water content of Arctic, midlatitude, and tropical cirrus, J. Geophys. Res., 113, D24208, doi:10.1029/2008JD010342, 2008.

Schumann, U.: On the effect of emissions from aircraft engines on the state of the atmosphere, Ann. Geophys., 12, 365-384, 1994, http://www.ann-geophys.net/12/365/1994/.

Schumann, U.: On conditions for contrail formation from aircraft exhausts, Meteorol. Z., 5, 4-23, 1996.

Schumann, U.: Contrail cirrus, in: Cirrus, edited by: Lynch, D. K., Sassen, K., O'Starr, C. D., and Stephens, G., Oxford Univ. Press, Oxford, 231-255, 2002.

Schumann, U.: A contrail cirrus prediction model, Geosci. Model Dev., 5, 543-580, doi:10.5194/gmd-5-543-2012, 2012.

Schumann, U. and Graf, K.: Aviation-induced cirrus and radiation changes at diurnal timescales, J. Geophys. Res., 118, 2404-2421, doi:10.1002/jgrd.50184, 2013.

Schumann, U., Graf, K., and Mannstein, H.: Potential to reduce the climate impact of aviation by flight level changes, in: 3rd AIAA Atmospheric and Space Environments Conference, AIAA paper 2011-3376, 1-22, Honolulu, Hawaii, 2011a.

Schumann, U., Mayer, B., Gierens, K., Unterstrasser, S., Jessberger, P., Petzold, A., Voigt, C., and Gayet, J.-F.: Effective radius of ice particles in cirrus and contrails, J. Atmos. Sci., 68, 300-321, doi:10.1175/2010JAS3562.1, 2011b.

Schumann, U., Graf, K., Mannstein, H., and Mayer, B.: Contrails: visible aviation induced climate impact, in: Atmospheric Physics - Background - Methods - Trends, edited by: Schumann, U., Springer, Berlin, Heidelberg, doi:10.1007/978-3-64230183-4_15, 239-257, 2012a.

Schumann, U., Mayer, B., Graf, K., and Mannstein, H.: A parametric radiative forcing model for contrail cirrus, J. Appl. Meteorol. Clim., 51, 1391-1406, doi:10.1175/JAMC-D-11-0242.1, 2012 b.

Schumann, U., Hempel, R., Flentje, H., Garhammer, M., Graf, K., Kox, S., Lösslein, H., and Mayer, B.: Contrail study with ground-based cameras, Atmos. Meas. Tech., 6, 3597-3612, doi:10.5194/amt-6-3597-2013, 2013a.

Schumann, U., Jeßberger, P., and Voigt, C.: Contrail ice particles in aircraft wakes and their climatic importance, Geophys. Res. Lett., 40, 2867-2872, doi:10.1002/grl.50539, 2013b.

Spangenberg, D. A., Bedka, S. T., Palikonda, R., Duda, D. P., and Rose, F. G.: Contrail radiative forcing over the Northern Hemi- sphere from 2006 Aqua MODIS data, Geophys. Res. Lett., 40, 595-600, doi:10.1002/grl.50168, 2013.

Spichtinger, P. and Gierens, K. M.: Modelling of cirrus clouds Part 1a: Model description and validation, Atmos. Chem. Phys., 9, 685-706, doi:10.5194/acp-9-685-2009, 2009.

Stephens, G. L., O'Brien, D., Webster, P. J., Pilewski, P., Kato, S., and Li, J.-L.: The albedo of Earth, Rev. Geophys., 53, 141-163, doi:10.1002/2014RG000449, 2015.

Stubenrauch, C. J., Rossow, W. B., Kinne, S., Ackerman, S., Cesana, G., Chepfer, H., Girolamo, L. D., Getzewich, B., Guignard, A., Heidinger, A., Maddux, B. C., Menzel, W. P., Minnis, P., Pearl, C., Platnick, S., Poulsen, C., Riedi, J., SunMack, S., Walther, A., Winker, D., Zeng, S., and Zhao, G.: Assessment of global cloud datasets from satellites, B. Am. Meteorol. Soc., 94, 1031-1049, doi:10.1175/BAMS-D-12-00117.1, 2013.

Unterstrasser, S.: Large eddy simulation study of contrail microphysics and geometry during the vortex phase and consequences on contrail-to-cirrus transition, J. Geophys. Res.-Atmos., 119, 7537-7555, doi:10.1002/2013JD021418, 2014.

Unterstrasser, S. and Gierens, K.: Numerical simulations of contrail-to-cirrus transition - Part 2: Impact of initial ice crystal number, radiation, stratification, secondary nucleation and layer depth, Atmos. Chem. Phys., 10, 2037-2051, doi:10.5194/acp-102037-2010, 2010a.

Unterstrasser, S. and Gierens, K.: Numerical simulations of contrail-to-cirrus transition - Part 1: An extensive parametric study, Atmos. Chem. Phys., 10, 2017-2036, doi:10.5194/acp-102017-2010, 2010b.

Unterstrasser, S. and Görsch, N.: Aircraft-type dependency of contrail evolution, J. Geophys. Res., 119, 14015-14025, doi:10.1002/2014JD022642, 2014.

Unterstrasser, S., Sölch, I., and Gierens, K.: Cloud resolving modeling of contrail evolution, in: Atmospheric Physics - Background - Methods - Trends, edited by: Schumann, U., Springer, Heidelberg, doi:10.1007/978-3-642-30183-4_33, 543-559, 2012.

Vay, S. A., Anderson, B. E., Sachse, G. W., Collins, J. E., Podolske, J. R., Twohy, C. H., Gandrud, B., Chan, K. R., Baughcum, S. L., and Wallio, H. A.: DC-8-based observations of aircraft $\mathrm{CO}, \mathrm{CH}_{4}, \mathrm{~N}_{2} \mathrm{O}$, and $\mathrm{H}_{2} \mathrm{O}(\mathrm{g})$ emission indices during SUCCESS, Geophys. Res. Lett., 25, 1717-1720, doi:10.1029/98GL00656, 1998.

Vázquez-Navarro, M., Mayer, B., and Mannstein, H.: A fast method for the retrieval of integrated longwave and shortwave top-of-atmosphere upwelling irradiances from MSG/SEVIRI (RRUMS), Atmos. Meas. Tech., 6, 2627-2640, doi:10.5194/amt6-2627-2013, 2013.

Vázquez-Navarro, M., Mannstein, H., and Kox, S.: Contrail life cycle and properties from one year of MSG/SEVIRI rapid-scan images, Atmos. Chem. Phys., 15, 8739-8749, doi:10.5194/acp-158739-2015, 2015.

Voigt, C., Schumann, U., Jurkat, T., Schäuble, D., Schlager, H., Petzold, A., Gayet, J.-F., Krämer, M., Schneider, J., Borrmann, S., Schmale, J., Jessberger, P., Hamburger, T., Lichtenstern, M., Scheibe, M., Gourbeyre, C., Meyer, J., Kübbeler, M., Frey, W., Kalesse, H., Butler, T., Lawrence, M. G., Holzäpfel, F., Arnold, F., Wendisch, M., Döpelheuer, A., Gottschaldt, K., Baumann, R., Zöger, M., Sölch, I., Rautenhaus, M., and Dörnbrack, A.: In-situ observations of young contrails - overview and selected results 
from the CONCERT campaign, Atmos. Chem. Phys., 10, 90399056, doi:10.5194/acp-10-9039-2010, 2010.

Voigt, C., Schumann, U., Jessberger, P., Jurkat, T., Petzold, A., Gayet, J.-F., Krämer, M., Thornberry, T., and Fahey, D. W.: Extinction and optical depth of contrails, Geophys. Res. Lett., 38, L11806 doi:10.1029/2011GL047189, 2011.

Voigt, C., Minikin, A., Schumann, U., and ML-CIRRUS_team: ML-CIRRUS - the HALO mission on mid latitude cirrus clouds, EGU General Assembly, Vienna, Austria, EGU2015-2758, 2015.

Wang, M. and Penner, J. E.: Cirrus clouds in a global climate model with a statistical cirrus cloud scheme, Atmos. Chem. Phys., 10, 5449-5474, doi:10.5194/acp-10-5449-2010, 2010.

Wilcox, L. J., Shine, K. P., and Hoskins, B. J.: Radiative forcing due to aviation water vapour emissions, Atmos. Environ., 63, 1-13, doi:10.1016/j.atmosenv.2012.08.072, 2012.

Wilkerson, J. T., Jacobson, M. Z., Malwitz, A., Balasubramanian, S., Wayson, R., Fleming, G., Naiman, A. D., and Lele, S. K.: Analysis of emission data from global commercial aviation: 2004 and 2006, Atmos. Chem. Phys., 10, 6391-6408, doi:10.5194/acp-10-6391-2010, 2010.

Yang, P., Hong, G., Dessler, A. E., Ou, S. S. C., Liou, K.-N., Minnis, P., and Harshvardhan: Contrails and induced cirrus - optics and radiation, B. Am. Meteorol. Soc., 91, 473-478, 2010.
Yi, B., Yang, P., Liou, K.-N., Minnis, P., and Penner, J. E.: Simulation of the global contrail radiative forcing: a sensitivity analysis, Geophys. Res. Lett., 39, L00F03, doi:10.1029/2012GL054042, 2012.

Yun, Y. and Penner, J. E.: Global model comparison of heterogeneous ice nucleation parameterizations in mixed phase clouds, J. Geophys. Res., 117, 7203-7203, doi:10.1029/2011JD016506, 2012.

Yun, Y., Penner, J. E., and Popovicheva, O.: The effects of hygroscopicity on ice nucleation of fossil fuel combustion aerosols in mixed-phase clouds, Atmos. Chem. Phys., 13, 4339-4348, doi:10.5194/acp-13-4339-2013, 2013.

Zhang, Y., Macke, A., and Albers, F.: Effect of crystal size spectrum and crystal shape on stratiform cirrus radiative forcing, Atmos. Res., 52, 59-75, doi:10.1016/S0169-8095(99)00026-5, 1999.

Zhou, C. and Penner, J. E.: Aircraft soot indirect effect on largescale cirrus clouds: is the indirect forcing by aircraft soot positive or negative?, J. Geophys. Res., 119, 11303-11320, doi:10.1002/2014JD021914, 2014. 